Experimental investigations on the resistance of masonry walls with AAC thermal break layer

Peer-reviewed author version

DEYAZADA, Mohammed; VANDOREN, Bram; DRAGAN, Dan \& DEGEE, Herve (2019) Experimental investigations on the resistance of masonry walls with AAC thermal break layer. In: CONSTRUCTION AND BUILDING MATERIALS, 224, p. 474-492.

DOI: 10.1016/j.conbuildmat.2019.06.205

Handle: http://hdl.handle.net/1942/28998 


\title{
Experimental investigations on the resistance of masonry walls with AAC thermal break layer
}

\author{
M. Deyazada ${ }^{\mathrm{a}, *}$, B. Vandoren ${ }^{\mathrm{a}}$, D. Dragan ${ }^{\mathrm{a}}$, H. Degee $^{\mathrm{a}}$ \\ ${ }^{a}$ Construction Engineering research group, University Hasselt, 3590 Diepenbeek, Belgium
}

\begin{abstract}
An experimental research on the resistance of composite masonry walls is presented. The composite specimens considered herein are load-bearing masonry walls comprising two types of masonry units (i.e. regular masonry units with one layer of thermal break elements). The focus regarding the thermal elements has been put on isolation layers made of aerated autoclaved concrete (AAC). The research included extensive laboratory experiments on small and medium scale of homogeneous and composite specimens (stacked blocks and masonry wallets) under uniaxial compression load with and without eccentricity. The experimental results show that the interaction between masonry and thermal elements has a positive influence on the local bearing resistance of the thermal break layer because of the stiffening brought by the upper masonry layers. Based on this observation, interaction factors are proposed. In addition, results indicate that the global strength reduction due to eccentricity showed to be slightly more severe for composite walls in comparison with the homogeneous specimens.
\end{abstract}

Keywords: Thermal break elements, AAC, Composite masonry walls, Load bearing resistance, Eurocode 6

\section{Introduction}

\subsection{Background}

Masonry is one of the most essential construction materials and techniques through the history of mankind for its high durability, ability to resist

\footnotetext{
*Corresponding author

Email address: mohammed.deyazada@uhasselt.be (M. Deyazada)
} 
5 important vertical loads and effective construction cost [1]. The latest evolutions in Europe with respect to the environmental issues have influenced the design of the buildings on thermal and structural aspects. The European Commission plans to reduce the energy consumption to $20 \%$ by 2020 [2], thus the new buildings should follow the concept of low energy consumption. A general principle for improving the thermal performance of a given building is to ensure the continuity of thermal insulations all around the building 3]. This leads to the implementation of insulating solutions and thermal elements aiming at a low global thermal conductivity [4. As presented in Figure 1a, typical cavity walls as used in UK, Belgium and in the Netherlands consist in a relatively thin load-bearing wall (10 to $20 \mathrm{~cm}$ ), a facing non-bearing wall and a thick thermal insulation layer in between. In addition, the use of thermal break elements at the bottom of the load bearing walls (i.e. at the level of the wall-floor junctions) has proven to be necessary to avoid thermal bridges (see Figure 1b). Examples of materials which can be used as bottom layer of the wall to eliminate the thermal bridge effect are Aerated Autoclaved Concrete (AAC) [5], cellular glass [5] [6], or combinations of polymer concrete inserts and polystyrene [4, 7]. AAC is a light building material (volumetric mass density ranges from 250 to $800 \mathrm{~kg} / \mathrm{m} 3$ ) made from lime cement and sand [8, 9] and characterized by a compressive 25 strength up to $4.5 \mathrm{MPa}$ [10, 11], where cellular glass is a $100 \%$ inorganic lightweight material characterized by limited bearing strength ranging from 2.5 to $3.2 \mathrm{MPa}$ [6, 12]. The present investigation is specifically focusing on load bearing walls essentially made of clay or concrete units and resorting to AAC as thermal break layer. Although the three materials involved in these combinations are separately covered by the current material and stability standards, like for instance EN 771 or EN 1996, the consequence of their combined use in terms of strength and stability of walls made for their main part either of clay or concrete units, with AAC units limited to the lower part on a height of less than 1/10th of the total height of the wall, remains an open question. 


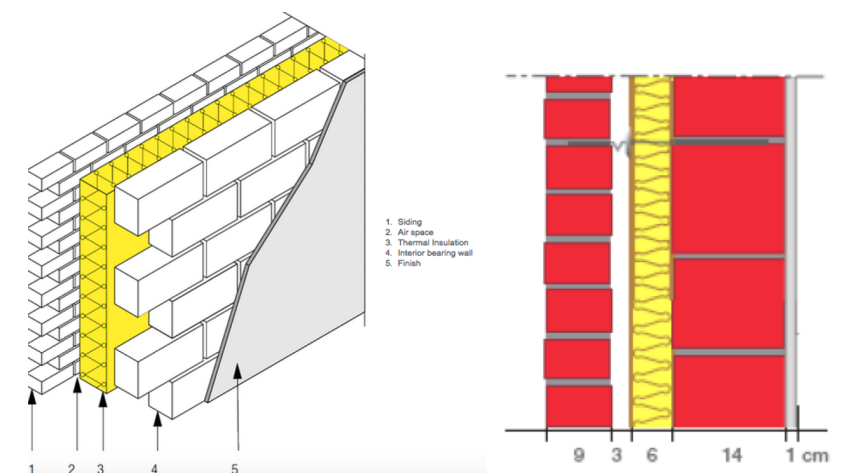

(a) [3, 13]
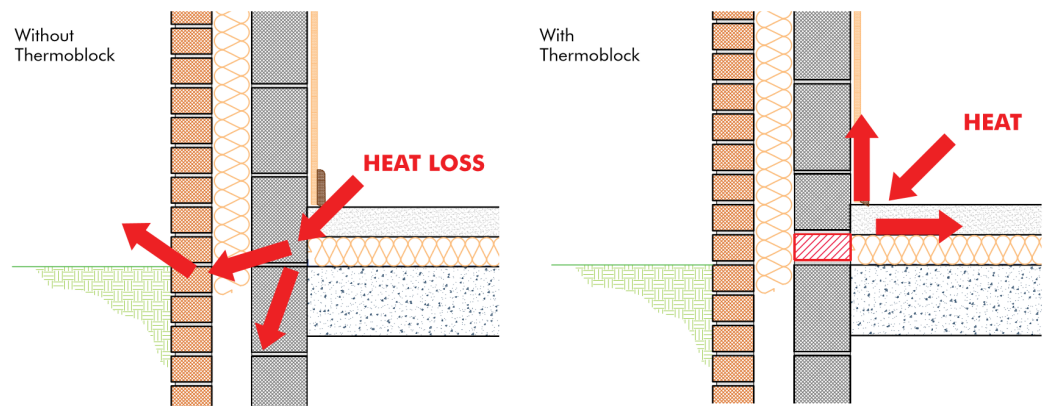

(b) 14

Figure 1: (a) Typical cavity wall in Belgium; (b) insulating elements to eliminate thermal bridge

The bearing capacity of conventional homogeneous masonry walls against vertical centered and non-centered compression has been investigated by many research studies via direct testing of masonry walls, e.g. [15 21]. The aim of these tests was essentially to assess the failure mode of the masonry walls and to get knowledge on the stress-strain characteristics, in order to further elaborate on the structural behavior by deriving suitable theoretical formulations. Such studies allow as well the validation of either sophisticated or simplified numerical models such as finite element models and equivalent frame models [22 34] to be used in the design of new structures or the assessment of existing structures. Research results are also available concerning the structural performance of AAC when used as load bearing material in classical homogeneous walls [9, 35, 36, but so far not in composite combinations. Up to date, only limited information is available concerning the structural resistance of composite masonry structures. Martens [12] conducted a research 
study on small scale composite walls using cellular glass as thermal layer to characterize their compressive resistance. The study pointed out that the compressive strength of the wallets was mainly governed by the resistance of the thermal layer but that an influence of the upper masonry units was also clearly identified. Another study by Mordant [13] has been carried out to walls including a rubber layer at their bottom for acoustic reasons. It was concluded that the presence of this material has a favorable impact on the structural behavior in terms of failure mechanisms, energy dissipation and strain capacity. In addition, the latest draft of Eurocode 6 [37] currently subjected to vertical loading. It indicates as general rule that the load capacity of the wall $N_{R d}$ should be determined using the strength properties of the weakest material, thus not accounting for interaction. It is however stated that, in case one of the types of units used in the wall presents holes, the interaction could lead to a global strength smaller than the strength of the weakest of both materials and that this should be assessed by testing. Relying on the above analysis of the situation, this paper presents the results of a broad experimental investigation aiming at a better understanding of the compression behavior of unreinforced masonry walls including AAC units as bottom layer and subjected to vertical compression loads with or without eccentricity. The main objective of this investigation is to identify the failure mechanism of such composite walls in view of developing suitable design procedures. Experimental tests have been carried out in four phases, namely (i) Conventional compression tests on single units (24 tests), (ii) Centered

(ii) Centered compression tests (iii) Centered compression tests on homogeneous and composite masonry wallets (two sets of wallets, one build with a quality control of the products and execution and the other one without any specific control of the execution - 41 tests) and (iv) Compression tests on homogeneous and composite walls with eccentricity including different amplitudes of the eccentricity of the compression load (15 tests). The adopted test setup, the geometry of the specimens, the combinations considered, and the tests results are described and discussed below. 


\section{Tests on masonry units}

The first part of the characterization deals with the behavior of masonry units in terms of ultimate compression strength and failure behavior. As presented in Figure 2, the experimental campaign covered different materials and geometrical properties, namely AAC solid unit, two types of perforated clay units, each of them characterized by a different nominal compression strength, and hollow aggregate concrete blocks. Twenty-four units were tested under uniaxial compression (six specimens per type). More details regarding the nominal geometrical and strength properties of the considered units are given in Table 1 .

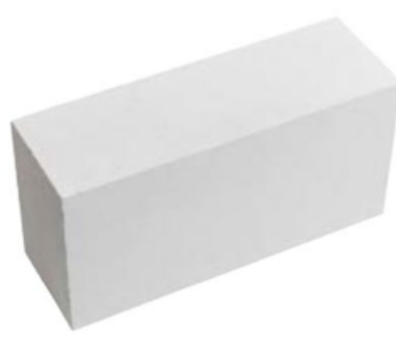

(a)

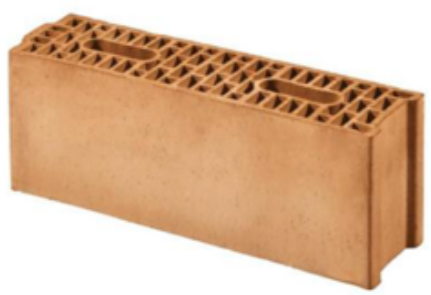

(b)

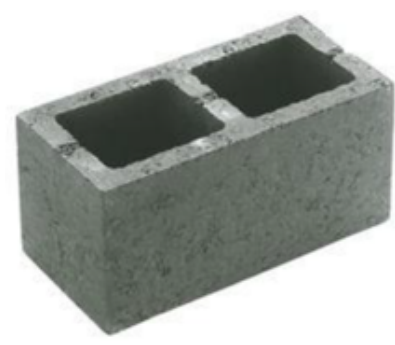

(c)

Figure 2: Masonry units of the experimental campaign: (a) AAC unit; (b) perforated clay unit; (c) concrete aggregate hollow block

Table 1: Overview of the units of the experimental campaign

\begin{tabular}{lcccccc}
\hline No. & Name & Symbol & $\begin{array}{c}\mathrm{L} \\
(\mathrm{mm})\end{array}$ & $\begin{array}{c}\mathrm{t} \\
(\mathrm{mm})\end{array}$ & $\begin{array}{c}\mathrm{h} \\
(\mathrm{mm})\end{array}$ & $\begin{array}{c}\text { Declared strength } \\
(\mathrm{MPa})\end{array}$ \\
\hline 1 & AAC & A & 600 & 150 & 200 & 4.5 \\
2 & Perforated clay & CL10 & 500 & 135 & 184 & $\geq 10$ \\
3 & Perforated clay & CL15 & 500 & 135 & 184 & $\geq 15$ \\
4 & Hollow concrete & C & 290 & 138 & 190 & 15 \\
\hline
\end{tabular}

Note: Declared strength is the minimum strength value guaranteed by the provider as available on the product data sheet

The tests were carried out according to the European Standard EN 772-1 
temperature. AAC units were conditioned to a moisture content of $6 \%$ where clay and concrete blocks have been conditioned to the air dry condition (i.e. specimens stored for at least 14 days at $15{ }^{\circ} \mathrm{C}$ temperature and $65 \%$ humidity). The clay and AAC units were cut to half of their length to fit within the compression testing machine. The cutting of the units was made using a wet saw machine. To ensure full contact between the unit and the plates, and hence uniform loading, two steel plates were placed at the top and bottom of the specimen. Loads were applied with a loading rate of $0.05 \mathrm{~N} / \mathrm{mm}^{2} / \mathrm{s}$ for units having a nominal strength up to $10 \mathrm{~N} / \mathrm{mm}^{2}$ and $0.15 \mathrm{~N} / \mathrm{mm}^{2} / \mathrm{s}$ for units with 11 to $20 \mathrm{~N} / \mathrm{mm}^{2}$ compressive strength. Load cells were used to record the applied load and linear Variable Displacement Transducer (LVDTs) devices were used to measure the displacements. Two LVDTs were attached to the steel plates (one at the front side and one at the back side, see Figure 3). 

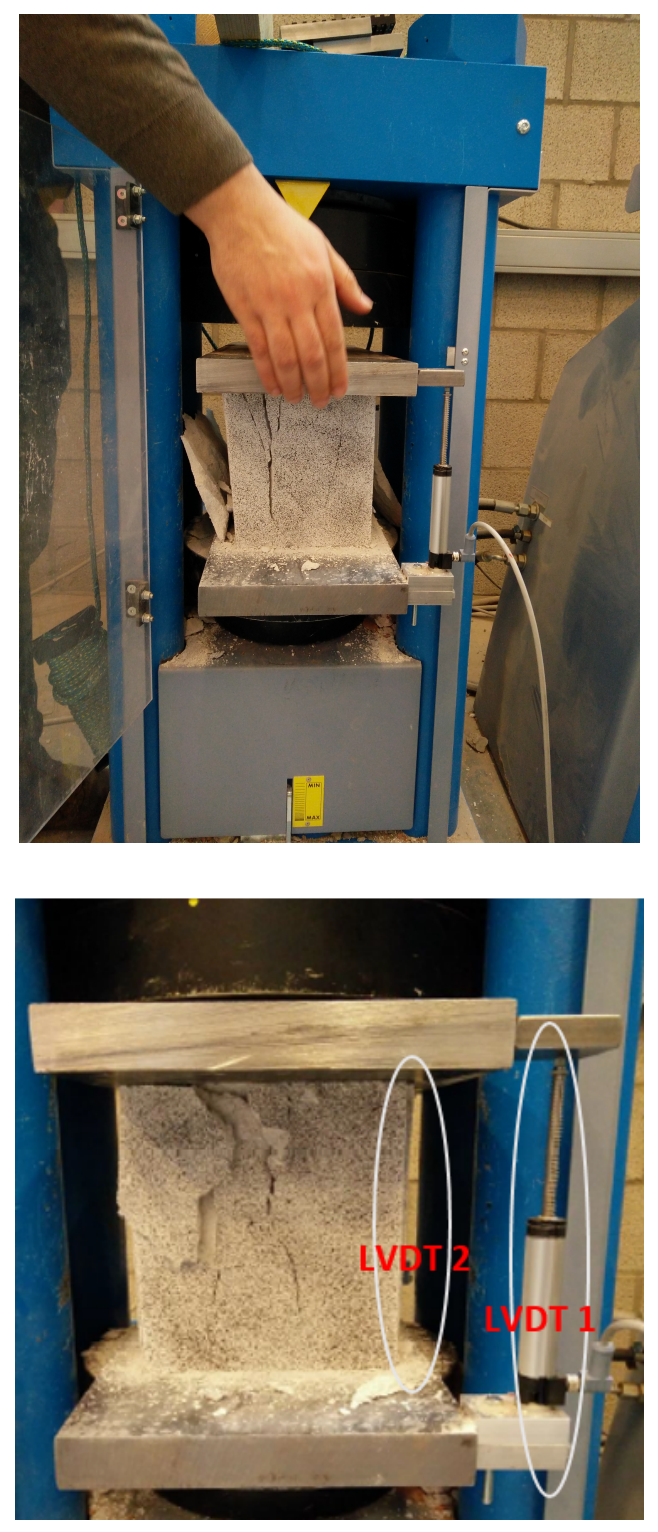

Figure 3: Test setup for the experimental characterization of single masonry units

The resistance of each specimen has been obtained by dividing the max110 imum load achieved by the gross area the unit. This value of the strength has been then converted into normalized compressive strength $f_{b}$ taking into account shape and conditioning factors using equation 1, according to the 
testing method described in EN 772-1 [38]-informative Annex A. Eq. 1 has been applied to all types of units except clay units of group 2 for which the normalized strength was taken equal to the mean measured strength, according to the common practice in the clay industry. The conditioning factor has been used to convert the measured compressive strength to an equivalent compressive strength hypothetically obtained in air-dry conditioning regime. The shape factor has then been used to convert the actual compressive strength of the masonry specimens to the normalized compressive strength of standardized reference specimens with dimensions equal to $100 \mathrm{~mm} \times 100 \mathrm{~mm} \times 100 \mathrm{~mm}$. The values adopted in this research for AAC and concrete units are given in Table 2. In addition, the modulus of elasticity in the loading direction $\left(E_{y}\right)$ of the units has been derived by taking a straight slope of the vertical stress-strain curve within a stress interval ranging from $5 \%$ to $50 \%$ of the ultimate load.

$$
f_{b}=f_{\text {mean }} \delta_{c} \delta
$$

Where:

$f_{b}$ is the normalized compressive strength of a single masonry unit;

$f_{\text {mean }}$ is the mean value of the strength specimens;

${ }_{130} \delta_{c}$ is conditioning factor;

$\delta$ is shape factor.

Table 2: Adopted shape and conditioning factor according to EN772-1 Annex A 38

\begin{tabular}{ccccc}
\hline Specimen & \multicolumn{2}{c}{ Shape factor } & \multicolumn{2}{c}{$\begin{array}{c}\text { Conditioning factor } \\
\text { Reference }\end{array}$} \\
& Value & Reference & Value & Table A.1 \\
A & 1.25 & 1 & moisture content of $6 \%$ \\
& & $\begin{array}{c}\mathrm{L}=200, \mathrm{~B}=140 \\
\text { Table A.1 }\end{array}$ & & \\
$\mathrm{C}$ & 1.24 & 1 & air dry condition \\
& & $\mathrm{h}=190, \mathrm{~L}=138$ & & \\
\hline
\end{tabular}

The experimental results on single units in terms of compression resistance and vertical deformation properties are displayed in Figures 4.7 . With regard to the AAC units (denoted "A" specimens), results show that the average value of the peak load was $152 \mathrm{kN}$, corresponding to $3.37 \mathrm{MPa}$ 
mean compressive strength (mean strength is represented by horizontal orange line, see Figure 4a). Moreover, the Young's modulus of the AAC units $E_{y}$ has been evaluated as $1111 \mathrm{MPa}$. The failure pattern of the AAC units displayed in Figure $4 \mathrm{~b}$ is characterized by a rather smooth post-peak behavior with softening. As a matter of comparison, similar tests carried out by Ferreti et al. 9] on AAC cube with $100 \mathrm{~mm}$ edge length have provided a mean compressive strength of AAC units equal to $3.1 \mathrm{MPa}$ and a vertical elastic modulus equal to $\mathrm{E}=1300 \mathrm{MPa}$.

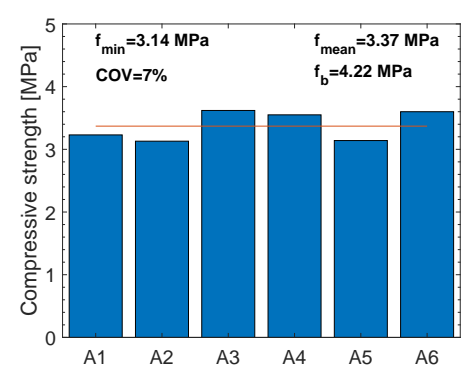

(a)

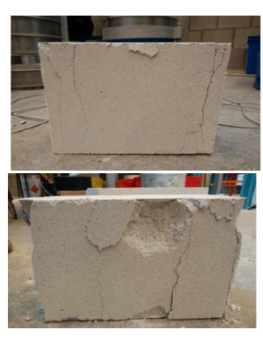

(b)

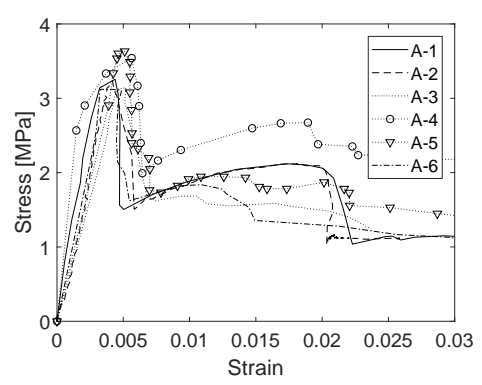

(c)

Figure 4: Test result of AAC units: (a) compressive strength; (b) typical failure pattern; (c) stress strain curve

145 "CL10" and "CL15" specimens) and on the concrete blocks (denoted "C" specimens) are displayed in Figures 5 to 7 . The average value of the load reached for clay units CL10 was $422 \mathrm{kN}$, which corresponds to $13.54 \mathrm{MPa}$ compression strength, while the average maximum load reached by the CL15 showed a similar cracking pattern, as shown in Figure 5b. The concrete units reached an average load of $560 \mathrm{kN}$ corresponding to $14.14 \mathrm{MPa}$ as compressive strength. The stress-strain curves of these units showed no post peak behavior but a brittle failure (see Figure $5 \mathrm{c}$, and $7 \mathrm{c}$ ). The average modulus of elasticity in the compression direction has been evaluated as 4012, 5611 and 2248 MPa respectively for clay units CL10, CL15 and concrete blocks. On the other hand, results were characterized by a larger compressive strength variability for concrete blocks with a coefficient of variation (COV) of $20 \%$ compared to a lower one for AAC or clay specimens (COV equal or 160

less than $8 \%$ ). 


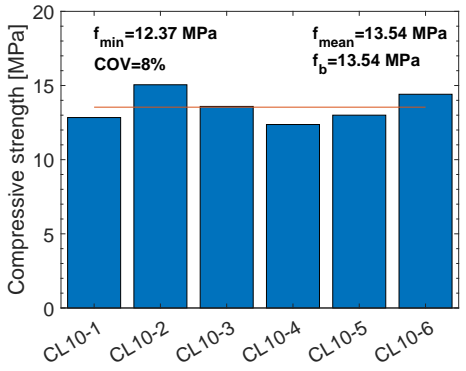

(a)

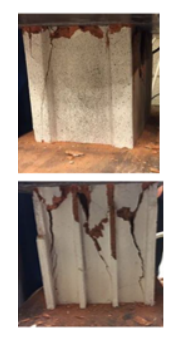

(b)

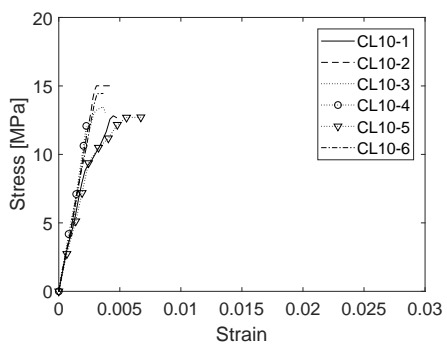

(c)

Figure 5: Test result of perforated clay units of $10 \mathrm{MPa}$ declared strength: (a) compressive strength; (b) typical failure pattern; (c) stress strain curve

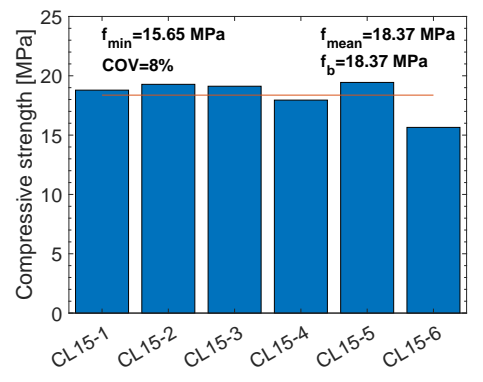

(a)

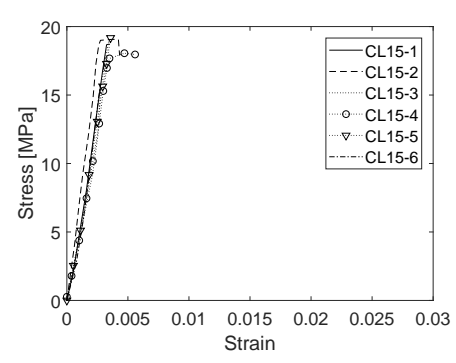

(b)

Figure 6: Test result of perforated clay units of $15 \mathrm{MPa}$ declared strength: (a) compressive strength; (b) stress strain curve

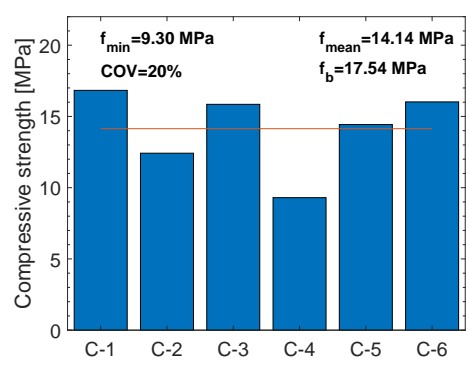

(a)

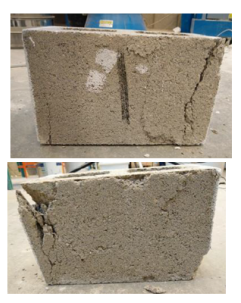

(b)

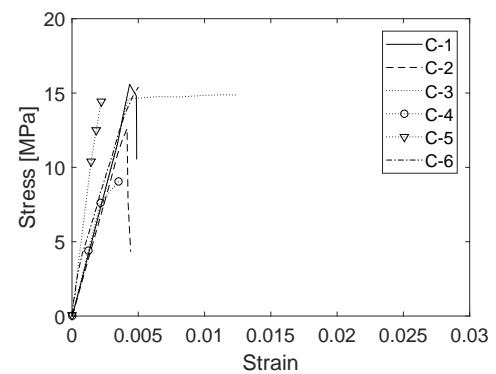

(c)

Figure 7: Test result of hollow concrete blocks: (a) compressive strength; (b) typical failure pattern; (c) stress strain curves 


\section{Tests on masonry duplets}

The second part of the experimental campaign deals with tests on masonry duplets made of two stacked units assembled with mortar. These duplets were contemplating different combinations of the four basic unit materials (A, CL10, CL15, C) and two types of mortar (General Purpose Mortar - GPM - and Thin-layer mortar - TLM -) with the purpose of studying the interaction between the AAC and the other types of units in terms of resulting resistance. Thickness of mortar layer was equal to $3 \mathrm{~mm}$ for TLM and to $10 \mathrm{~mm}$ for the GPM. The specimens were classified into two categories, namely homogeneous specimens covering six combinations (" $\mathrm{H}$ " specimens) and composite specimens ("C" specimens) covering four combinations (the top unit is an AAC one and the lower one is either clay or concrete). Six nominally identical specimens were fabricated for each combination with the exception of D-HCL15TLM and D-CCL15TLM (only 3 specimens for each). An overview of the tested combinations is given in Figure 8 . In addition, from each set of general purpose mortar made for masonry duplets, three samples of mortar were taken to characterize the compressive strength of the mortar (two set of mortar were used: first one for homogeneous clay $10 \mathrm{MPa}$ and composite AAC-clay duplets, second one for homogeneous concrete and composite AAC-concrete duplets). General purpose mortar was characterized according to EN1015. Results of this characterization are given in Table 3. The thin layer mortar was not specifically tested as no standardized test procedure is available and as the strength of systems with units assembled with TLM is known to be controlled essentially by the strength of the units (as translated by the strength formulation of EN 1996-1-1. 


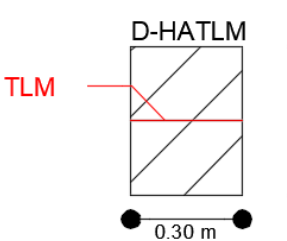

AAC

$+$

AAC

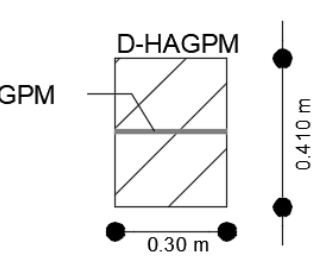

AAC

$+$

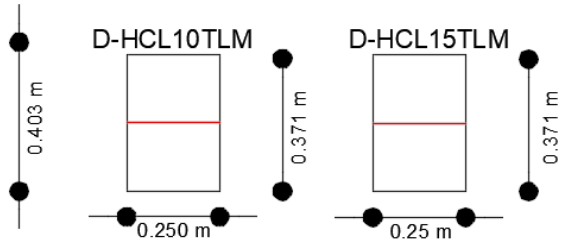

Clay10

$\stackrel{+}{\text { Clay10 }}$

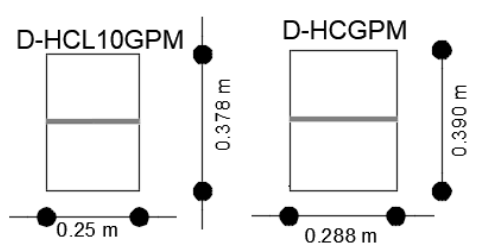

Clay 10

$+$

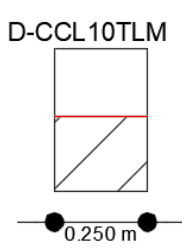

AAC

$+$

Clay 10

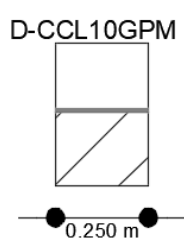

AAC

$+$

Clay 10

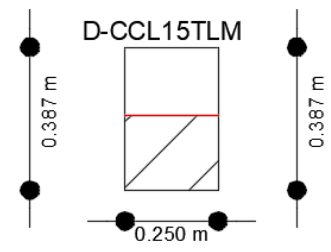

AAC

$+$

Clay 15

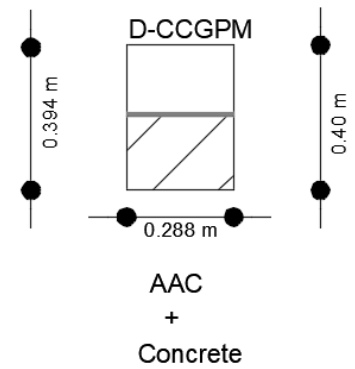

Figure 8: Overview of the tested combinations

The comparison between the " $\mathrm{H}$ " and "C" specimens in terms of their compressive strength allows a direct evaluation of the consequence of the interaction between two different materials (favorable or harmful) on the local strength.

Although some other researchers have conducted tests on similar small-scale stacked specimens (i.e. homogeneous AAC or concrete masonry stack of three units) [9, 25] with the aim of finding a correlation with tests on larger scale specimens, no commonly agreed specifications are available for the preparation and testing of such samples. Therefore, the present investigation essentially refers to EN1052-1 [39] for what regards the testing procedure, strength determination, etc. The test setup is presented in Figure 9. The axial compression load was applied through a hydraulic jack and increased continuously at a constant rate until failure occurred. The load was transferred from the jack to the specimen through a steel plate. With regard to the instrumentation, LVDTs measurement devices were used to evaluate the overall deformation shape of the specimens while a load cell was measuring the load applied by the hydraulic jack. A total of four LVDTs were placed at the top of the specimens to control the vertical displacement. The reference 
strength of each specimen in terms of stresses has been obtain by dividing the maximum load reached by the loaded gross area. The characteristic compressive strength for each group of specimens with the same configuration has been determined using Equation 2 or 3 (for combinations with 6 samples) [39], in which the greater value was selected if relevant:

$$
f_{k}=\frac{f}{1.2} \quad \text { or } \quad f_{k}=f_{\min } \quad \text { (whichever the smaller) }
$$

210 Where:

$f$ is the mean compressive strength;

$f_{\text {min }}$ is the smallest compressive strength of an individual masonry specimen.

$$
f_{k}=\mu-\alpha \times \sigma
$$

Where:

${ }_{215} \mu$ is the average compressive strength of the tested specimens;

$\alpha$ is calculated based on Student's t-distribution corresponding to the $5 \%$ fractile value based on a confidence level of $95 \%$;

$\sigma$ is the standard deviation. 

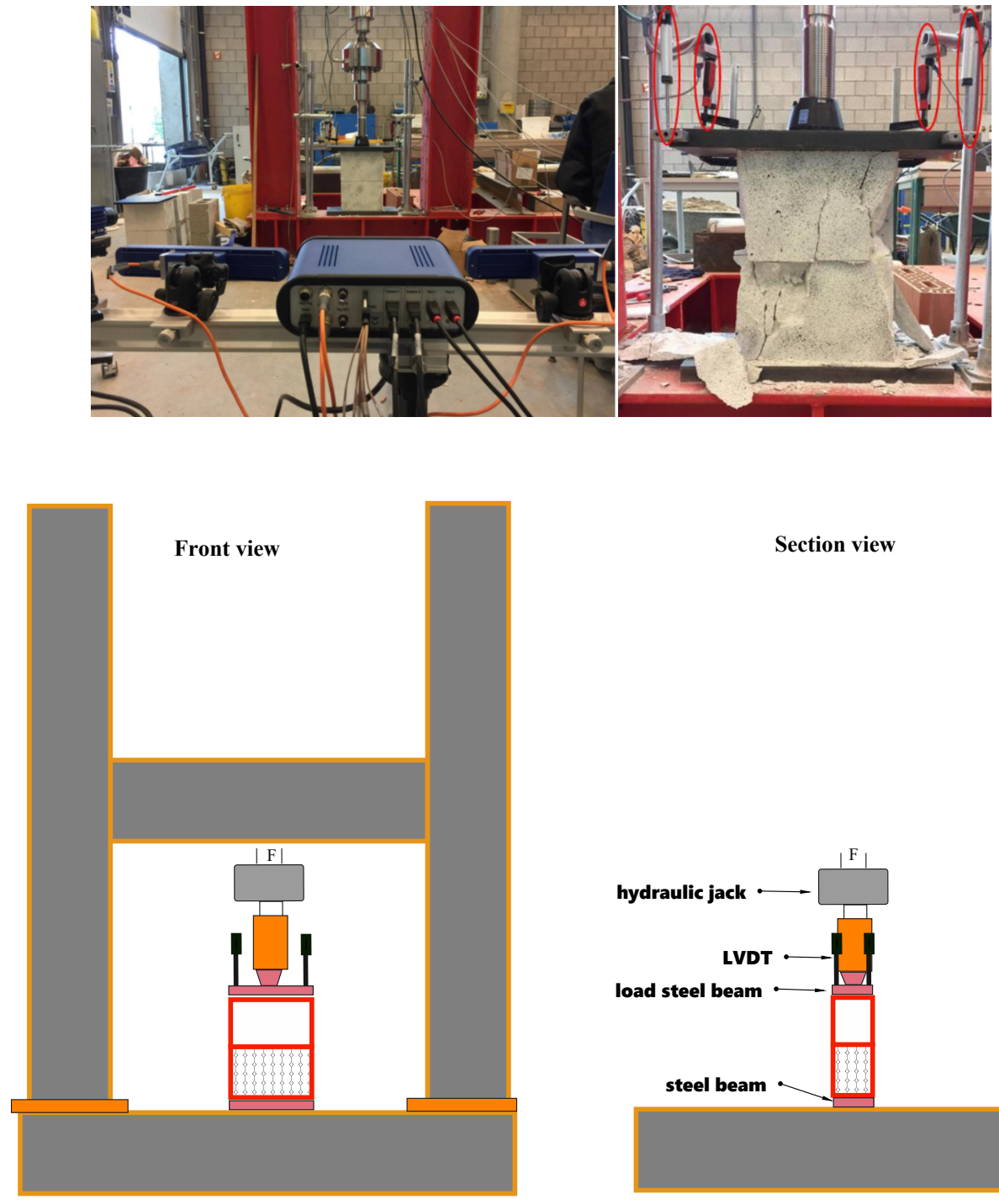

Section view

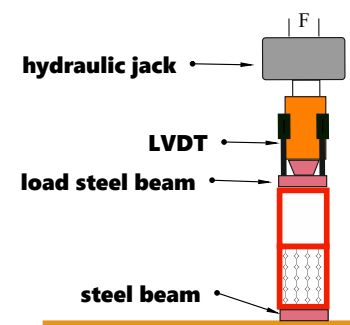

Figure 9: Test setup for the experimental characterization of masonry duplets

The test results on masonry duplets in terms of ultimate compressive strength, failure mechanism and stress-strain curves are displayed in Figures 10 to 12 . From the results, the following observations can be pointed out:

- From all homogeneous specimens, AAC duplets were characterized by 
the lowest resistance and clay CL15 duplets by the highest resistance. Concrete duplets with general purpose mortar were characterized with a higher strength than clay CL10 duplets whatever the mortar combinations.

- The comparison between homogeneous AAC and composite duplets with a given mortar combination showed that composite specimens were characterized by a higher strength than the corresponding homogeneous AAC ones, indicating a favorable influence of the regular load-bearing units on the local resistance of the thermal blocks. For instance, D-CCL10TLM specimens were stronger than D-HATLM and D-CCGPM specimens were stronger than D-HAGPM.

- The resistance reached by composite specimens for a given mortar combination was influenced by the type of non-AAC unit. For instance, D-CCL15TLM specimens were characterized by a higher resistance than D-CCL10TLM and D-CCGPM specimens were characterized by a higher resistance than D-CCL10GPM.

- AAC or clay duplets assembled with thin-layer mortar showed generally a higher resistance and a more limited strength variability than the corresponding ones built with general purpose mortar.

- The homogeneous AAC specimens showed a rather soft behavior associated with a large deformation capacity, in comparison to the very brittle behavior and the low deformation capacity for the homogeneous specimens built with clay or concrete masonry units (see Figure 12 ).

- The failure behavior of the composite specimens was always governed by the AAC elements. The crack pattern was however different from the corresponding homogeneous specimens. For the AAC-clay duplets built either with thin or general mortar, the failure of the clay unit is characterized by a single vertical or diagonal crack located close to the edge, while the AAC layer has experienced few cracks concentrating mainly at the corners. In the AAC-concrete duplets, the concrete units were undamaged while the duplets failed with cracking observed only in the AAC unit.

- The crack development at failure in the AAC units was more favorable in the composite specimens than in the corresponding homogeneous 
ones. This came from the constraining effect of the non-AAC unit, allowing a better spreading of the cracks in the weaker element. Cracks were also not directly propagating from the AAC layer to the other unit. This was particularly relevant for AAC-concrete combinations.

- The mechanical characterization of the general purpose mortar are displayed in terms of mean compressive strength. The strength of mortar appears as not influencing the global strength of the composite duplets, as their strength were mainly governed by the AAC units which were characterized by the lowest strengths. 


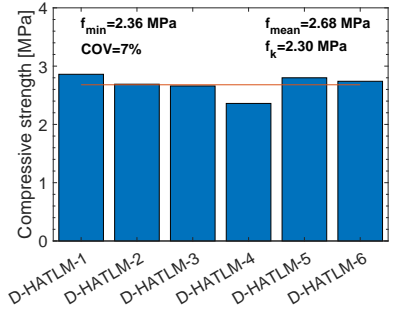

(a)

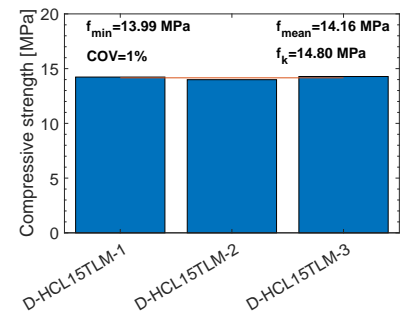

(d)

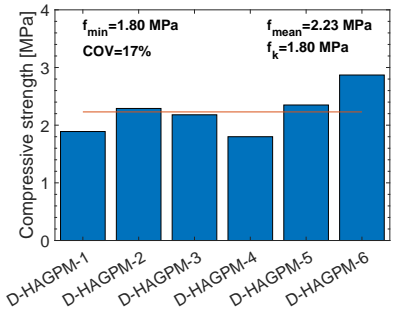

(b)

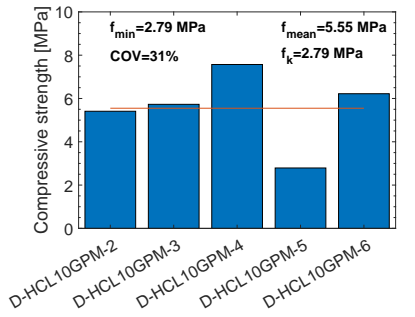

(e)

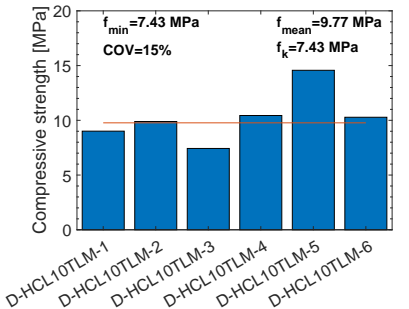

(c)

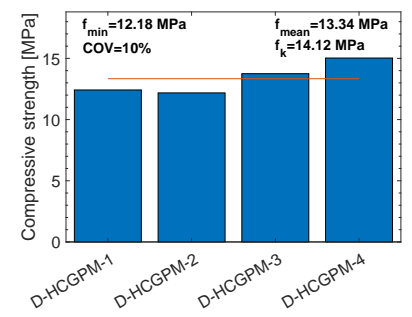

(f)

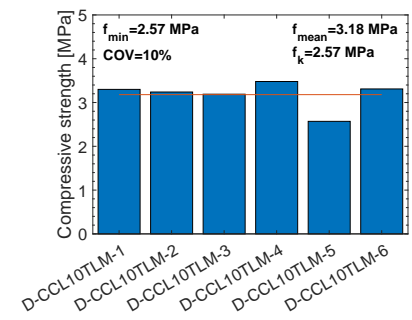

(g)

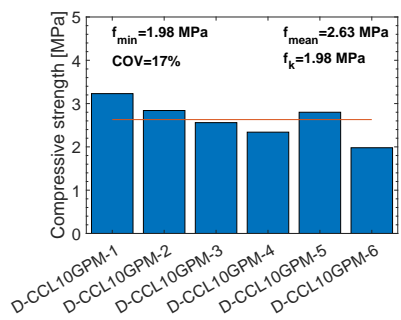

(i)

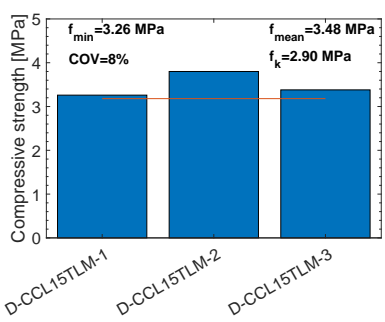

(h)

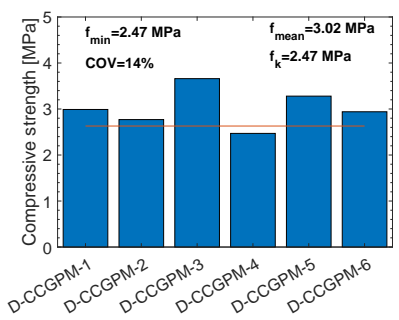

(j)

Figure 10: Compression strength of the masonry duplets: (a) homogeneous AAC with thin layer mortar; (b) homogeneous AAC with general purpose mortar; (c) homogeneous clay 10 with thin layer mortar; (d) homogeneous clay 15 with thin layer mortar; (e) homogeneous clay 10 with general purpose mortar; (f) homogeneous concrete with general purpose mortar; (g) composite AAC-clay 10 with thin layer mortar; (h) composite AACclay 15 with thin layer mortar; (i) composite AAC-clay 10 with general purpose mortar; (j) composite AAC-concrete with general purpose mortar 


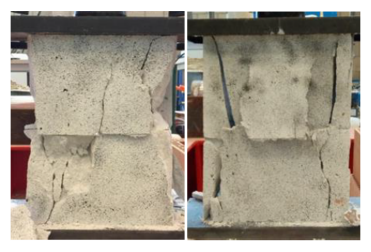

(a)

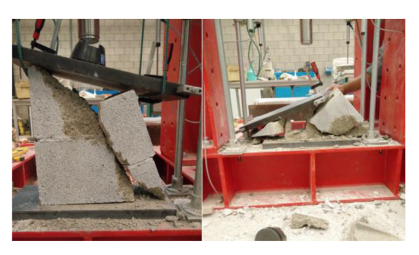

(d)

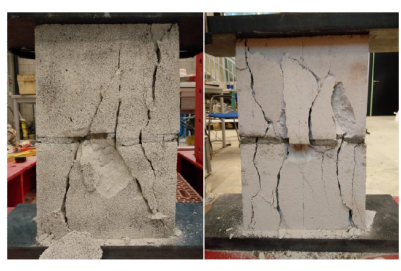

(b)

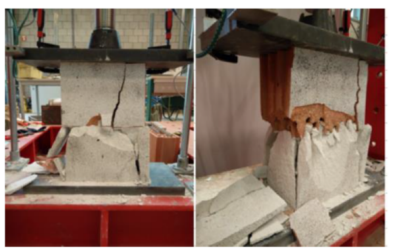

(e)

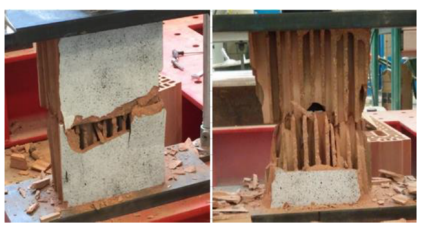

(c)

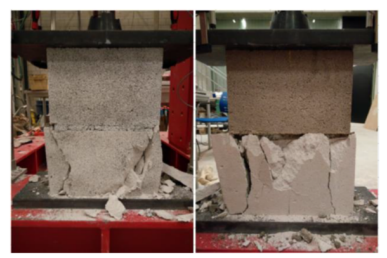

(f)

Figure 11: Failure pattern of the masonry duplets:Compression strength of the masonry duplets: (a) homogeneous AAC with thin layer mortar; (b) homogeneous AAC with general purpose mortar; (c) homogeneous clay 10 with thin layer mortar; (d) homogeneous concrete with general purpose mortar; (e) composite AAC-clay 10 with thin layer mortar; (f) composite AAC-concrete with general purpose mortar 


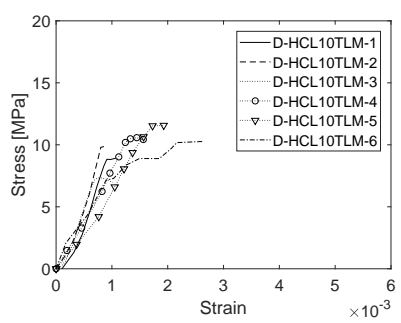

(a)

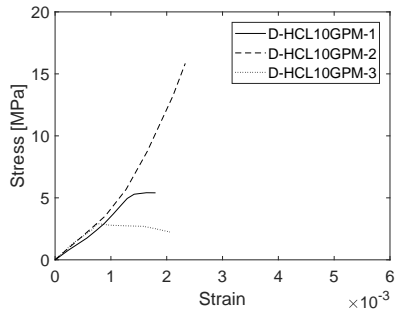

(c)

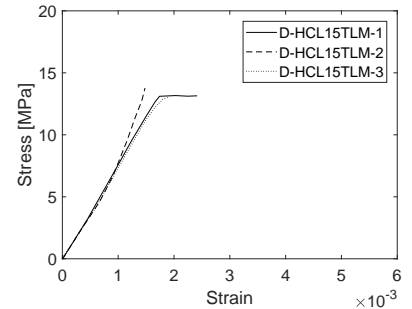

(b)

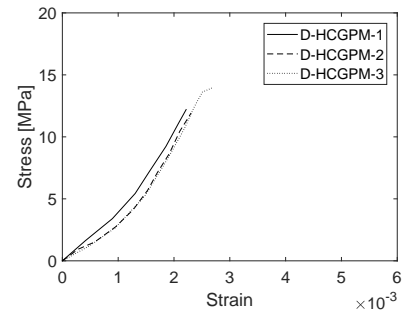

(d)

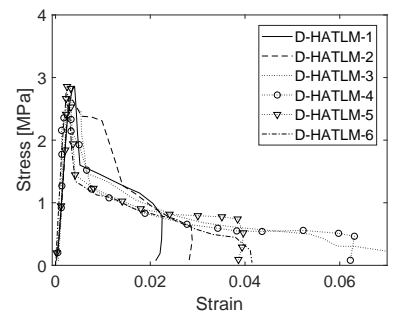

(e)

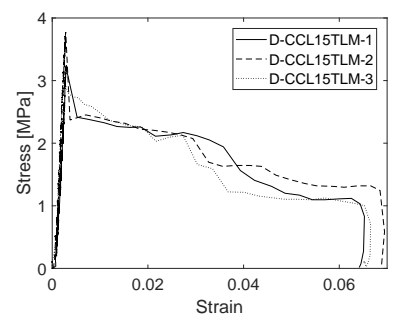

(h)

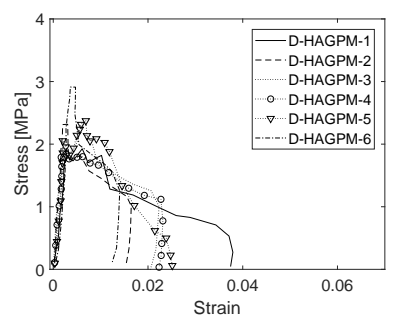

(f)

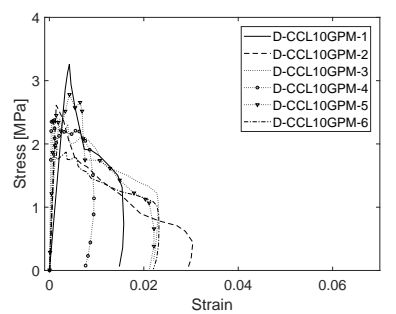

(i)

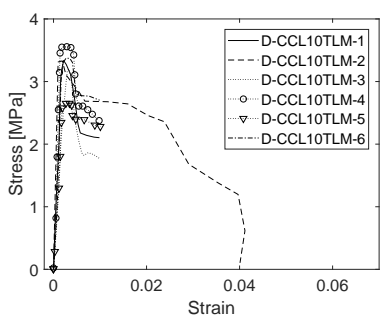

(g)

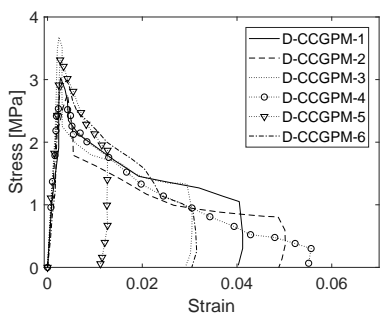

(j)

Figure 12: Stress strain curves of the masonry duplets: (a) homogeneous AAC with thin layer mortar; (b) homogeneous AAC with general purpose mortar; (c) homogeneous clay 10 with thin layer mortar; (d) homogeneous clay 15 with thin layer mortar; (e) homogeneous clay 10 with general purpose mortar; (f) homogeneous concrete with general purpose mortar; (g) composite AAC-clay 10 with thin layer mortar; (h) composite AACclay 15 with thin layer mortar; (i) composite AAC-clay 10 with general purpose mortar; (j) composite AAC-concrete with general purpose mortar 
Table 3: Compression strength of the mortar of the masonry duplets

\begin{tabular}{|c|c|c|}
\hline $\begin{array}{l}\text { Specimen } \\
\text { name }\end{array}$ & D-HCL10GPM D-CCL10GPM & D-HCGPM D-CCGPM \\
\hline $\begin{array}{l}\text { Mortar mean } \\
\text { strength }[\mathrm{MPa}]\end{array}$ & 24.62 & $19.64 \mathrm{MPa}$ \\
\hline
\end{tabular}

\section{Tests on masonry wallets under centered compression}

The third part of the experimental campaign deals with tests on masonry wallets under centered compression, with the aim of characterizing the bearing resistance of the composite masonry walls in terms of their compressive strength in comparison to the homogeneous situation. Similar to the previous stage, the wallets were considering different combinations of the four basic elements (A, CL10, CL15, C) and two types of mortar (General Purpose Mortar - GPM - and Thin-layer mortar - TLM -). The global set of 275 tested wallets comprised two sub-sets fabricated according to different quality control of the execution: the first group included walls built with no specific quality control while the second one was fabricated under the control of technical advisers of the company providing the AAC blocks, ensuring thus an ideal implementation of all their execution recommendations. As a matter of fact, such a difference would practically correspond to different values of the partial safety factor $\gamma_{M}$ according to the current Belgium annex to Eurocode 6 [40]. The specific measures recommended by the producers of the AAC units implemented in the second group of wallets were essentially the following. Firstly, the boundary conditions at the base of the AAC layer were modified by implementing a general purpose mortar layer in order to limit irregularities of the interface and improve the load distribution within the AAC layer. Furthermore, a specific thin-layer mortar was used, with better adhesion properties to the AAC units. Finally, a wooden plank was placed between the specimens and the upper steel loading plate to soften the contact and hence improve the load distribution at the top of the wall. This latter aspect was however less likely to influence the final results than the first two, since its influenced mainly the load distribution in the upper units while the failure was always observed at the bottom of the wallet, triggered by the failure of the AAC units.

295 For the first group, two types of homogeneous wallets (homogeneous AAC 
wallets with thin-layer mortar denoted "W-HATLM" and Homogeneous AAC wallets with general purpose mortar denoted "W-HAGPM") and three configurations of composite walls (composite AAC-clay $10 \mathrm{MPA}$ with thin-layer mortar denoted "W-CCL10TLM", composite AAC-clay 15 MPa with thinlayer mortar denoted "W-CCL15TLM" and composite AAC-concrete with general purpose mortar denoted "W-CCGPM") were selected, including six specimens for each group. An overview of the specimens considered in the experimental campaign, including their general layout and geometrical parameters is presented in Figure 13. Homogeneous AAC walls assembled with general purpose mortar is clearly not the most usual way of erecting loadbearing AAC walls, but these specimens were made to allow a suitable comparison with the composite AAC-concrete combination where GPM is used as normal jointing system.
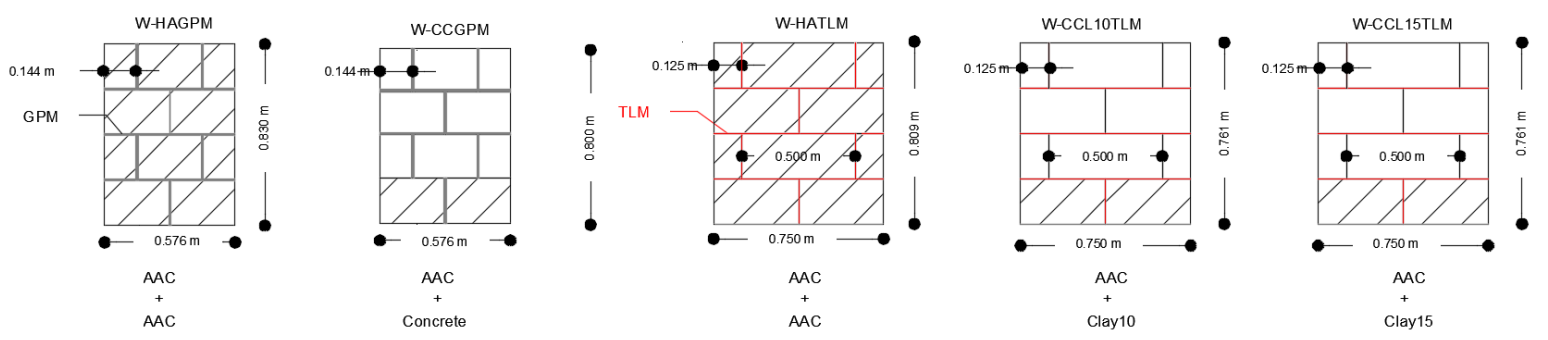

Figure 13: Overview of the wallets with no specific quality control

Three configurations were considered for the second group, namely homogeneous AAC wallets with thin-layer mortar (denoted "Wg-HATLM"), composite AAC-clay $10 \mathrm{MPa}$ with thin-layer mortar (denoted "Wg-CCL10TLM") and composite AAC-concrete wallets with general purpose mortar (denoted "Wg-CCGPM"). The layout of these specimens is displayed in Figure 14. 

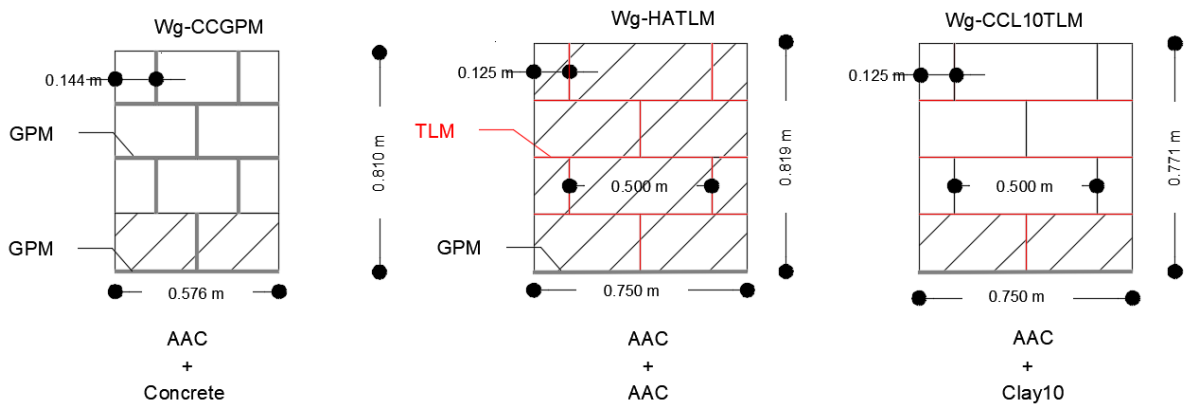

Figure 14: Overview of the wallets with quality control

The test setup used for the experimental characterization on masonry duplets has been adjusted to cope with the geometry of the wallets used in this test series. Tests were carried out by applying a compression vertical load centered on the masonry wallets by means of a vertical hydraulic jack. The load was applied at constant rate until the failure of the specimen (the total time interval to reach failure was about 15 to 30 minutes). The instrumentation comprised a combination of four LVDTs attached at the top steel plate to control the vertical displacement. In addition, an extra LVDT was placed at the level of the top of the first course of the wallet to measure the displacement at that level (see Figure 15). The strains plotted in figure 18 were derived from the average displacement obtained from the four LVDTs measuring the global shortening of the wallets. From the differential measurements obtained from these four LVDTs, the rotation of the top of the wallet was also controlled, showing a slight rotation during the accommodation phase of the specimen, followed by a pure translational displacement similar for all four devices during the actual loading phase. 

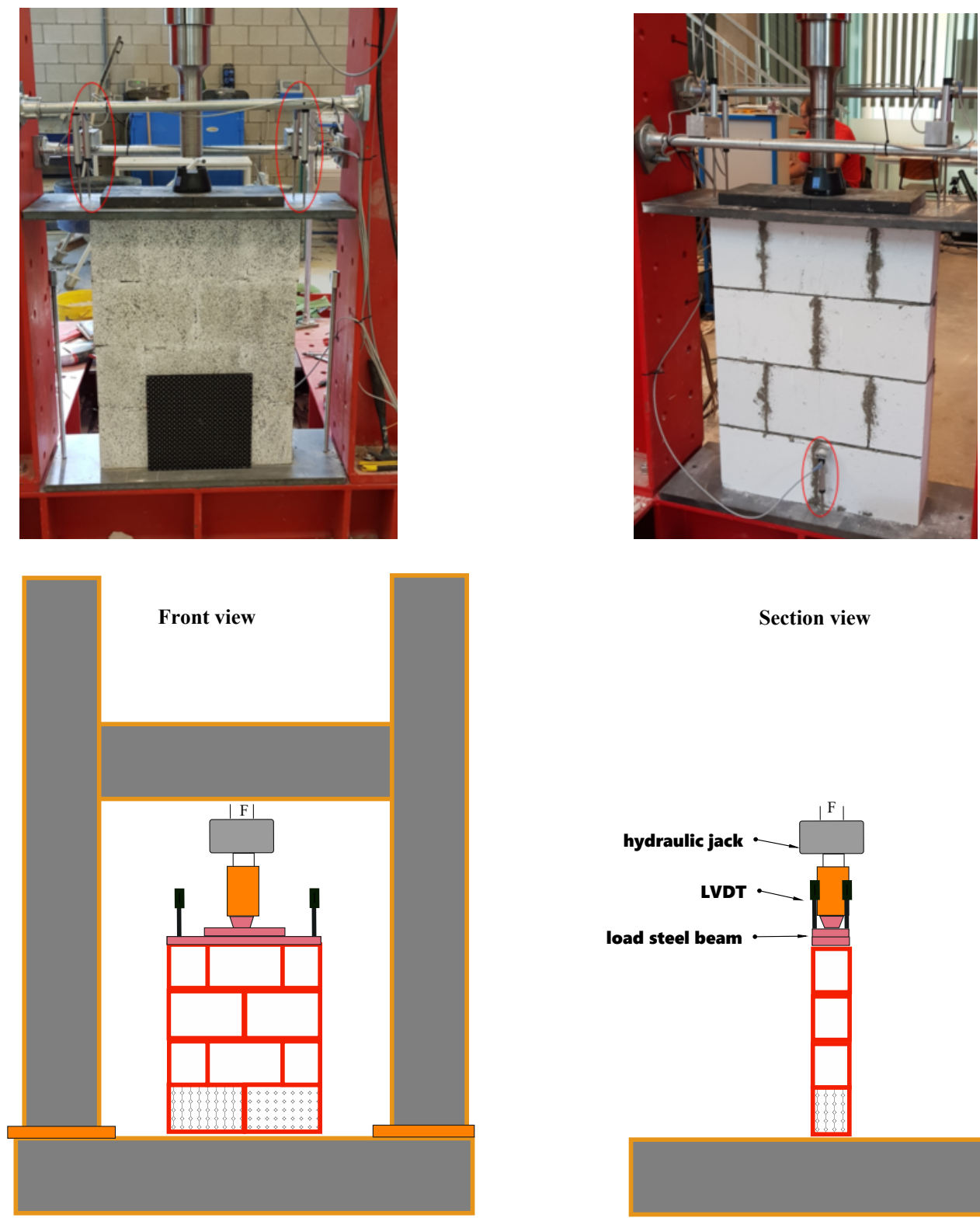

Section view

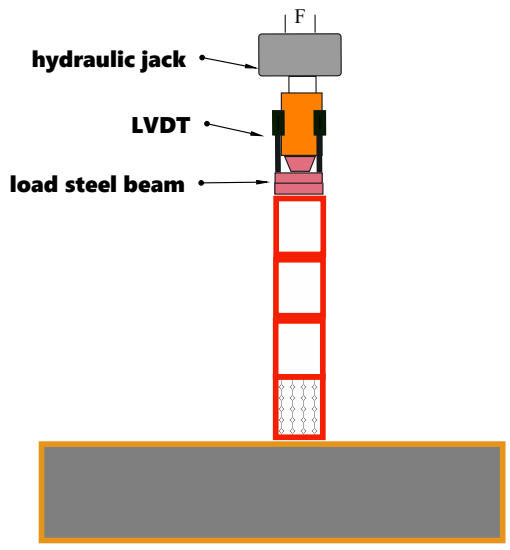

Figure 15: Test setup of for the experimental characterization of the masonry wallets

The observations from these experimental results on wallets can be sum- 
marized as follows:

- Results on wallets of both quality of execution agreed with the general trend of the tests on duplets: the composite specimens of both groups exhibited higher resistances than the corresponding homogenous AAC ones.

- The strength variability also tended to agree with previous results indicating a larger strength variation for homogenous AAC wallets with general purpose mortar (COV equal to 19\%) compared to a more limited variation for those built with thin-layer mortar (COV equal to 6\%). This can be related to the better compatibility of AAC with thin-layer mortar than with general purpose mortar.

- The quality of the execution influenced the average resistance of the specimens and its variability. For example, regarding the composite concrete wallets with general purpose mortar, the wallets built with controlled execution was characterized by a higher strength and a more limited variability than those built with no specific execution control $\left(f_{k}\right.$ equal to 3.32 and 2.22 MPa with COV equal 2 and $14 \%$ respectively).

- The failure pattern for tests on composite wallets showed a similar trend as for tests on duplets with the same combination, namely the failure of the specimens was governed by the AAC elements. In addition, the stress-strain curves showed that the strain at failure of the composite specimens was in general higher than for the corresponding homogeneous AAC specimens. As for the duplets, this can be related to the constraining influence of the masonry units of the upper layers.

- As shown in Table 4, the general purpose mortar had much greater strength than AAC units (up to five time greater). This explained also why the global strength of the composite walls is mainly governed the AAC elements.

- As a point of comparison regarding the behavior of homogeneous masonry, it can also be referred hereby to similar test results published by Ferreti et al. [9] on short AAC masonry wallets with thin layer mortar loaded in compression. In those tests, the measured mean compressive strength of $\mathrm{AAC}$ wallets was found equal to $2.56 \mathrm{MPa}$, i.e. a difference 

wallets without or with quality control respectively.

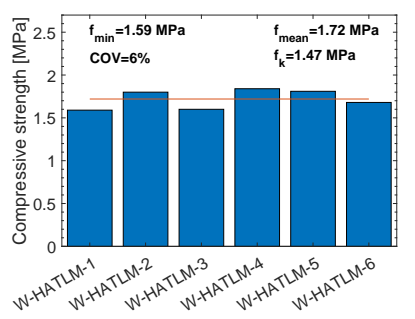

(a)

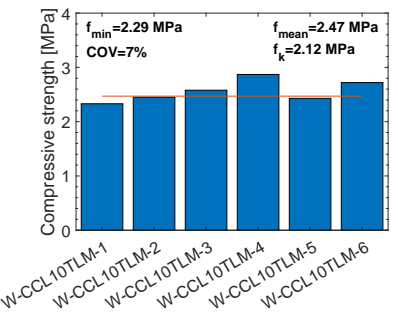

(c)

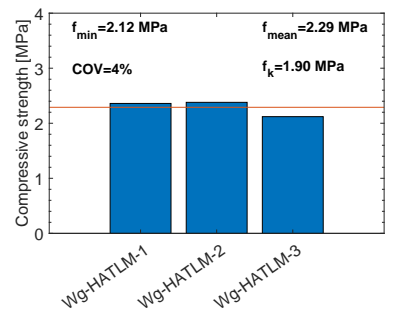

(f)

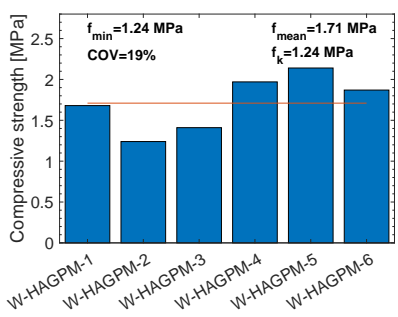

(b)

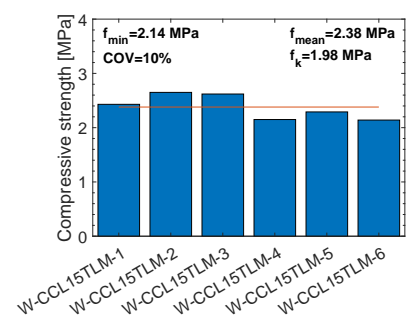

(d)

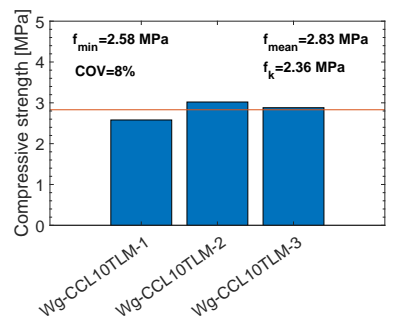

$(\mathrm{g})$

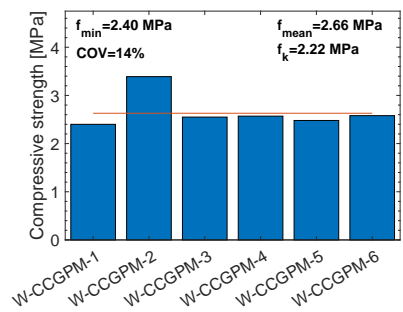

(e)

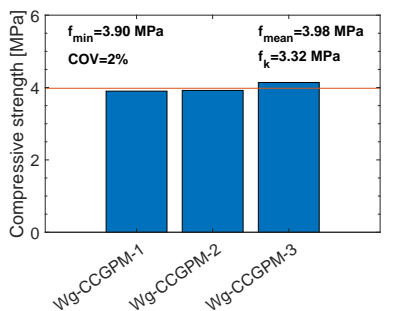

(h)

Figure 16: Compression strength of the masonry wallets without specific quality control (Figure 16-a to 16-e) or with (Figure 16-f to $16 \mathrm{~h}$ ) specific quality control: (a) homogeneous AAC with thin layer mortar; (b) homogeneous AAC with general purpose mortar; (c) composite AAC-clay 10 with thin layer mortar; (d) composite AAC-clay 15 with thin layer mortar; (e) composite AAC-concrete with general purpose mortar; (f) homogeneous AAC with thin layer mortar; (g) composite AAC-clay 10 with thin layer mortar; (h) composite AAC-concrete with general purpose mortar 

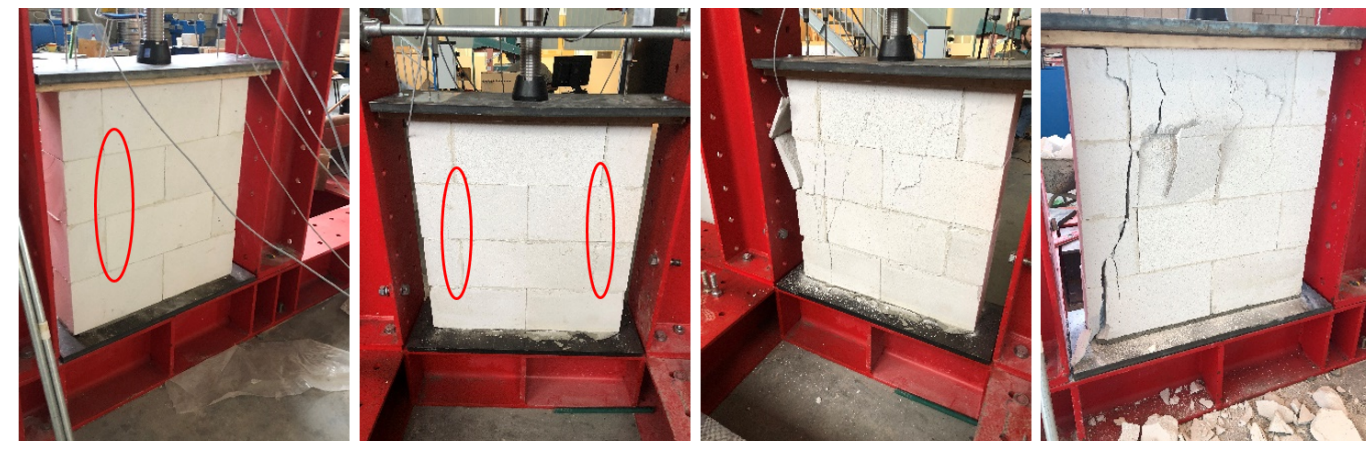

(a)
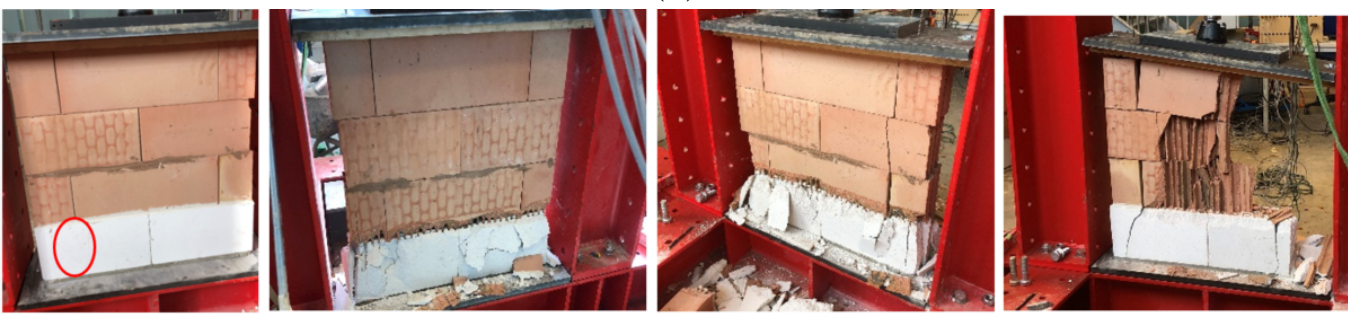

(b)
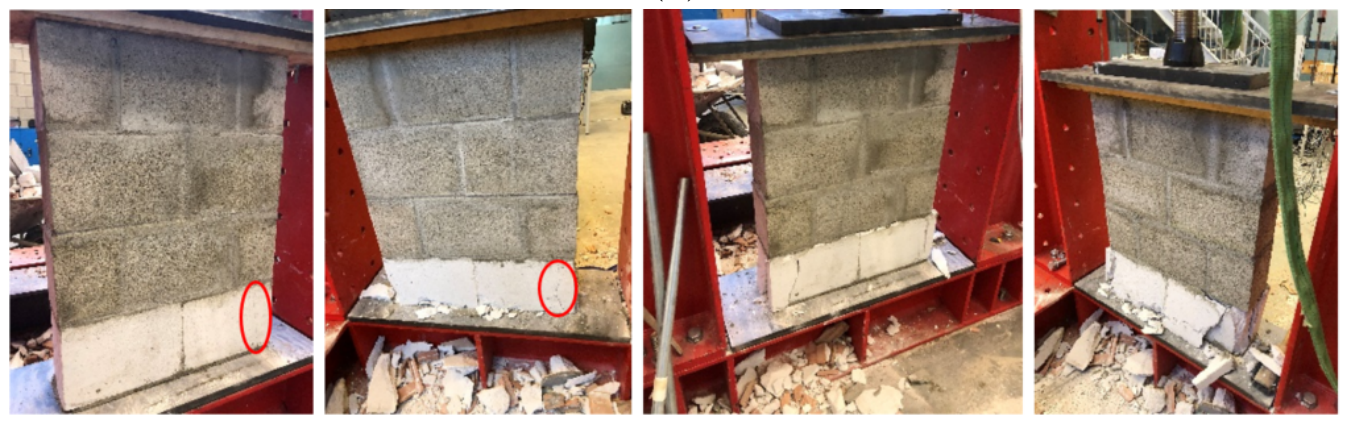

(c)

Figure 17: Failure pattern of the wallets with specific quality control: (a) homogeneous AAC with thin layer mortar; (b) composite AAC-clay 10 with thin layer mortar; (c) composite AAC-concrete with general purpose mortar 


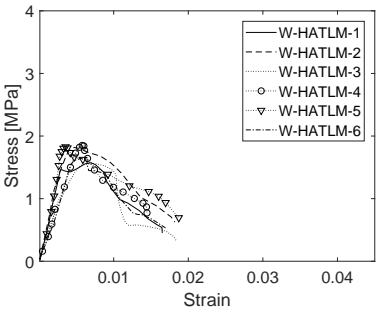

(a)

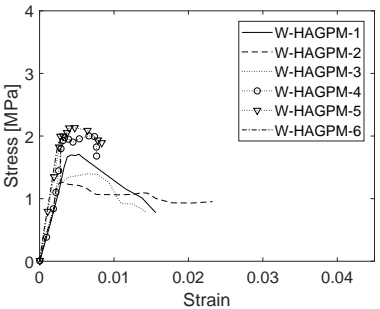

(b)

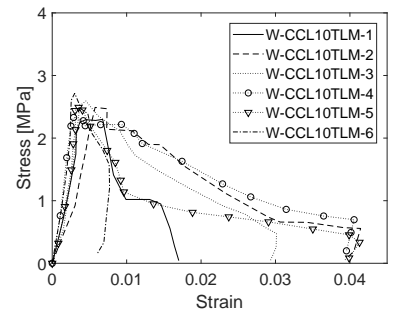

(c)

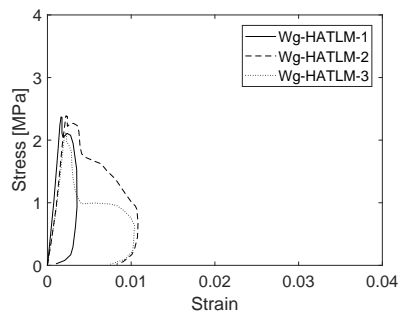

(f)

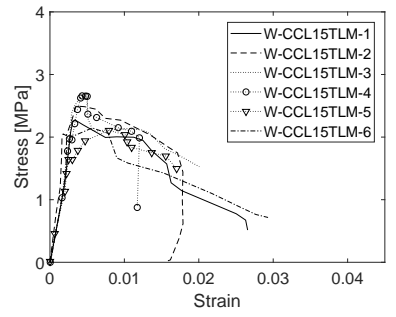

(d)

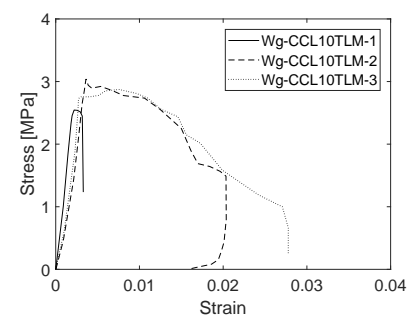

(g)

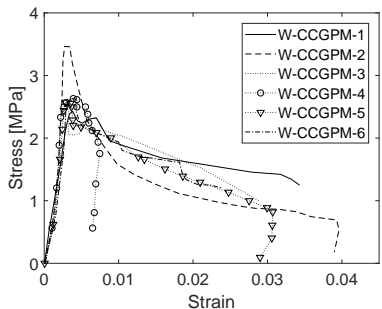

(e)

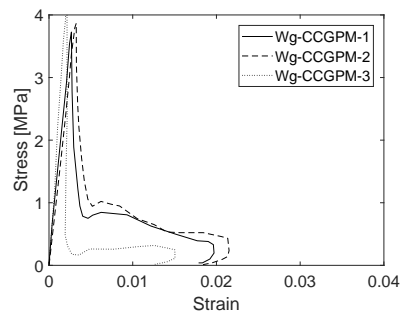

(h)

Figure 18: Stress strain curves of the masonry wallets without specific quality control (Figure 16-a to 16-e) or with (Figure 18f to 18 -h) specific quality control: (a) homogeneous AAC with thin layer mortar; (b) homogeneous AAC with general purpose mortar; (c) composite AAC-clay 10 with thin layer mortar; (d) composite AAC-clay 15 with thin layer mortar; (e) composite AAC-concrete with general purpose mortar; (f) homogeneous $\mathrm{AAC}$ with thin layer mortar; (g) composite AAC-clay 10 with thin layer mortar; (h) composite AAC-concrete with general purpose mortar 
Table 4: Compression strength of the mortar of the masonry duplets

\begin{tabular}{ccc}
\hline $\begin{array}{c}\text { Specimen } \\
\text { name }\end{array}$ & W-HAGPM & W-CCGPM \\
\hline $\begin{array}{c}\text { Mortar mean } \\
\text { strength [MPa] }\end{array}$ & 19.29 & 16.68 \\
\hline
\end{tabular}

\section{Tests on masonry wallets with eccentricity}

Since masonry is characterized by a low tensile strength, a possible eccentricity of the applied vertical compression loads, inducing a complementary global strength and stability of the wall [17]. Many authors [15, 18, 22 24, 32] have conducted experimental tests on different scale of masonry subjected to compression with varying eccentricity to evidence and quantify this effect for different materials and wall slenderness. For masonry elements with imporized by a splitting of the units with vertical cracks, accompanied by spalling and crushing along the masonry units. For slender walls (typically from a slenderness ratio larger than 18), failure occurs however due to a buckling instability characterized by the opening of bed joints at the mid-wall height. fluence of the eccentricity on their resistance and stability is not quantified yet, and relevant information is even not really available so far for homogeneous AAC walls. Therefore, this article presents results of experimental tests on homogeneous and composite wallets under different load eccentricity 385 as a first step towards a quantitative approach of the effect of eccentricity. The experimental campaign deals with tests on masonry wallets under compression considering a possible variation of the amplitude of the eccentricity of the reaction at the bottom of the wall (i.e. situation of a wall supported on part of its thickness) with the main aim of investigating the influence of applied on the strength of a centrically loaded wall in order to account for this eccentricity. This part included only tests on wallets built with quality control of the execution, in the sense defined in the previous section, and considering different amplitudes of the eccentricity of the reaction (i.e. $\mathrm{e}=\mathrm{t} / 6$; 
(i.e. layout, conditioning, loading, instrumentation) were similar to the centered compression tests described above. The steel plate located under the wallet was shifted in such a way that the wallet was not supported on its entire thickness, creating thus the desired eccentricity of the reaction. The supported width was respectively equal to $2 \mathrm{t} / 3$ and $\mathrm{t} / 3$, leading to eccentricities of $t / 6$ and $t / 3$. An overview of the considered specimens with the different considered eccentricities and a view of the test setup are given in Figure 19 and 20.
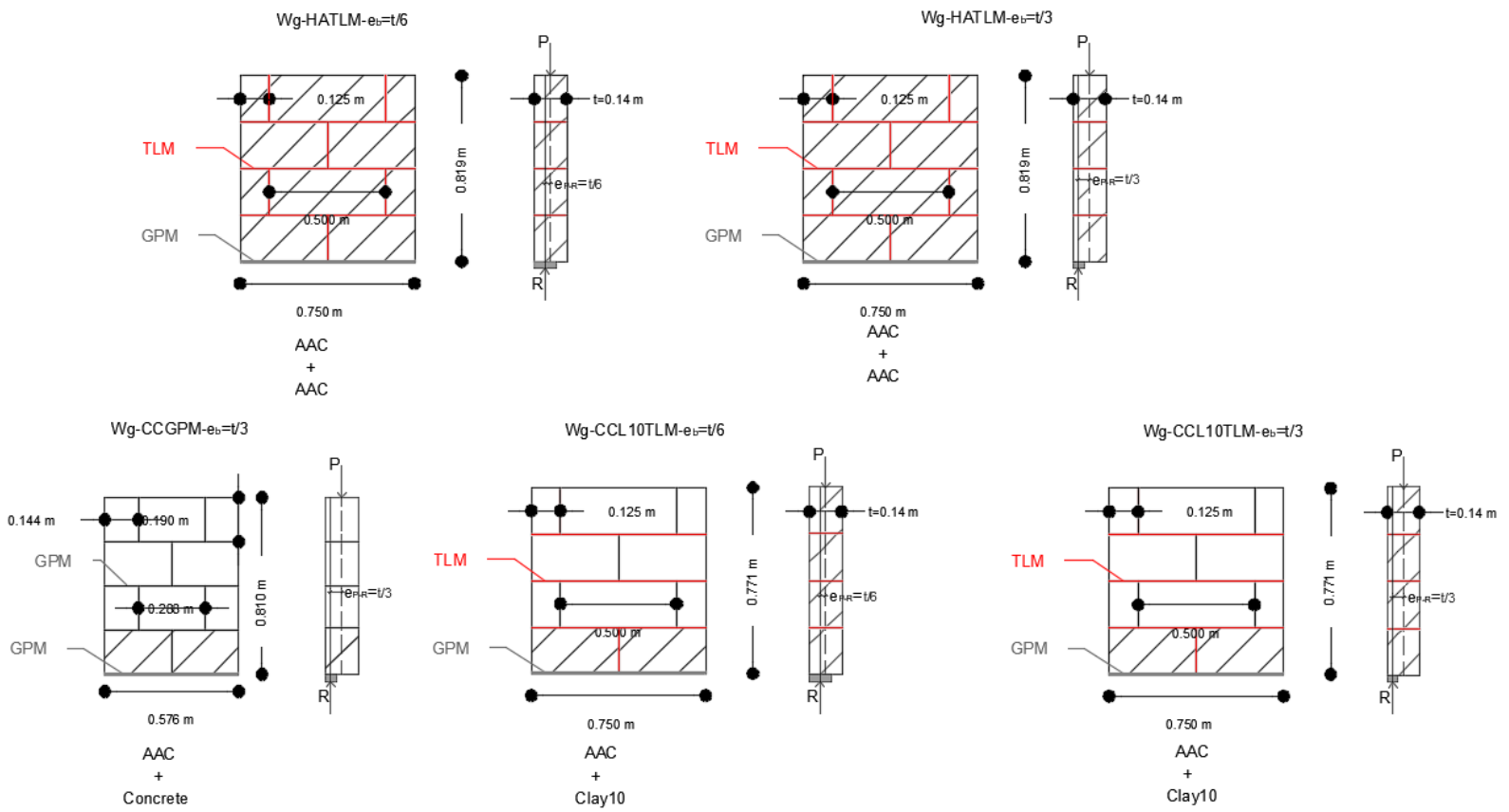

Figure 19: Overview of the specimens with eccentricity of the base reaction 

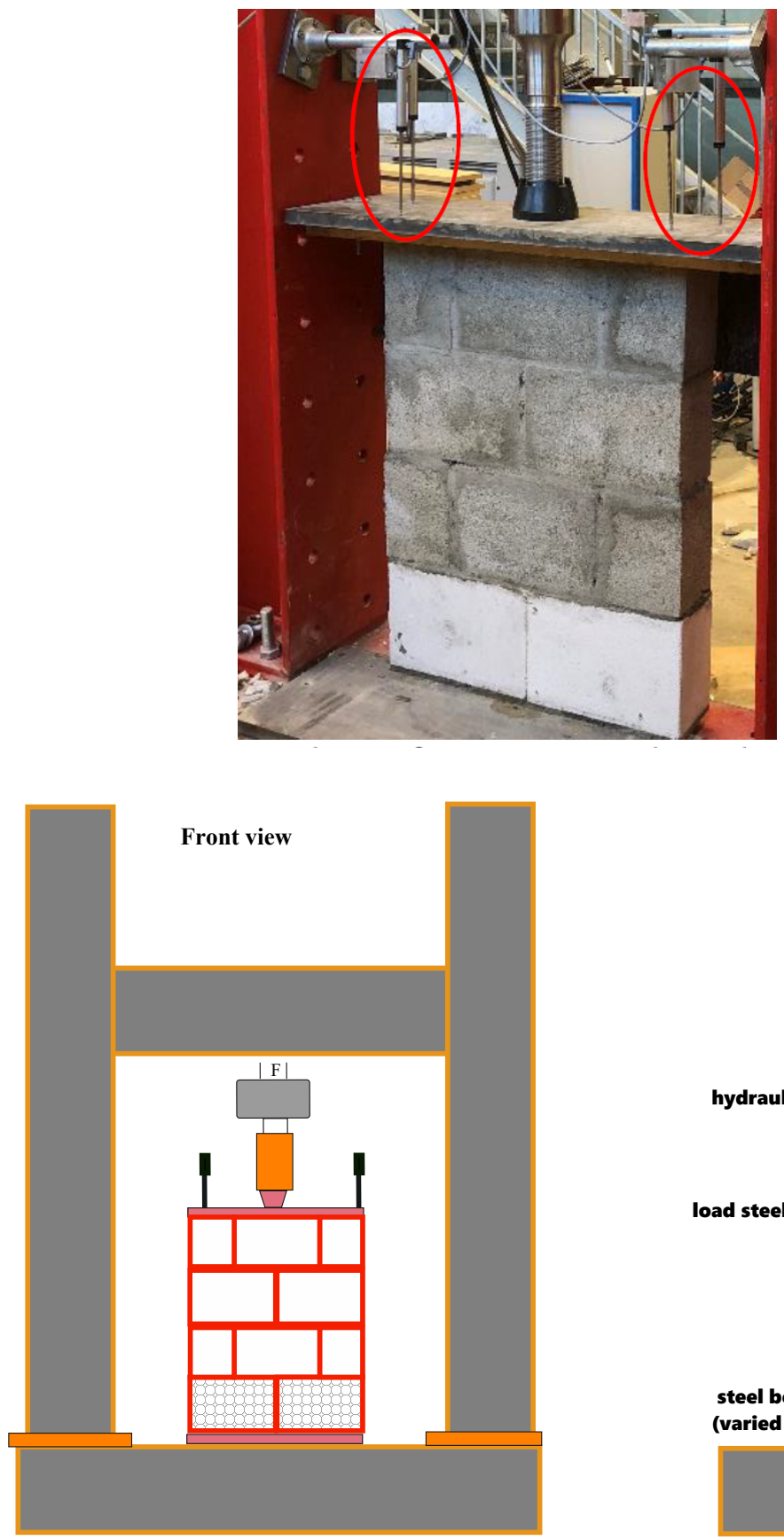

Section view

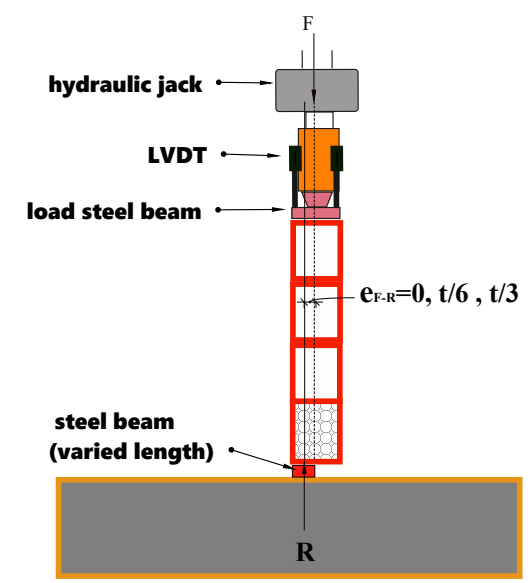

Figure 20: Test setup of for the experimental characterization of the masonry wallets under eccentricity 
The test results on wallets with eccentricity are presented in Figures 21 to 23 in terms of effective stress at failure $\sigma_{e f f}$, failure mechanism and stressstrain curves. The effective stress is defined as the total load divided by the total area of the wallets (i.e. $L \times t$, $\mathrm{t}$ is the total thickness). This definition of the stress includes thus both the effect of the material properties and of the eccentricity in a single parameter, in view of an easy comparison with the centered case. The distinction between the two effects is discussed further in section 6 . The experimental observations are summarized as follow:

- The results have shown the expected trend, i.e. reducing effective stress when increasing the eccentricity, for both homogeneous and composite wallets.

- As for the centered loading, the composite wallets were characterized with a higher effective stress at failure than the homogeneous AAC ones for the same magnitude of eccentricity.

- The variability of the compression resistance for each given eccentricity was limited. This can be related to the quality control of the execution of the specimens systematically implemented for this part of the tests.

- The failure of the homogeneous AAC wallets with non-centered base reaction was characterized by the initiation and development of vertical cracks at the bottom of the walls starting from the end of the supported zone. These cracks were then propagating towards the top of the wallet resulting in a "slicing" of the wallet (see Figure 22a). In contrast, the failure of the composite specimens started in the AAC layer due to the compression locally applied by the upper units in the zone overloaded by the bending moment created by the eccentricity. The initiation and the development of the cracks were thus mainly observed in the supported zone of the bottom layer (see Figures 22b and 22c).

- Composite AAC-concrete walls with a large eccentricity were characterized by a more severe strength reduction with respect to the corresponding configuration with non-centered reaction than what was observed for the composite AAC-clay. Characteristic values of the effective stress at failure for composite AAC-concrete reduced from 3.32 $\mathrm{MPa}$ for $\mathrm{e}=0$ to $0.80 \mathrm{MPa}$ for $\mathrm{e}=\mathrm{t} / 3$, compared to composite clay wallets reducing from 2.36 to $0.67 \mathrm{MPa}$. This can be explained by the 
concentration of the contact forces between concrete and AAC on a limited surface, i.e. the 3.65 centimeters of the outer shell of the hollow concrete block, while the contact forces remained better distributed on a larger nominal contact zone for the perforated clay units.

- Similarly to the tests with centered reaction, the composite wallets exhibited a better deformation capacity than the corresponding homogeneous AAC ones, showing the favorable influence of the interaction. On the other hand, the stress-strain curves have shown in general that the shortening at failure decreased when the amplitude of the eccentricity was increased.

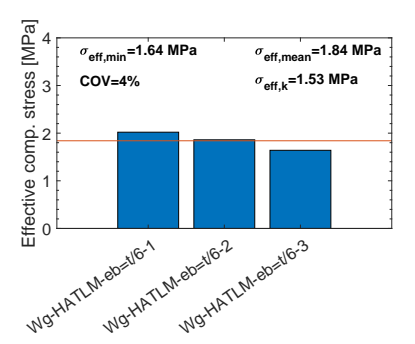

(a)

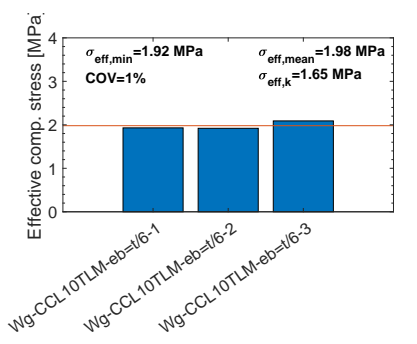

(b)

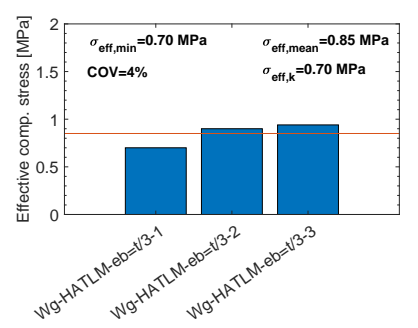

(c)

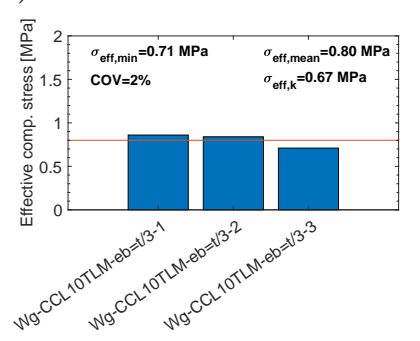

(d)

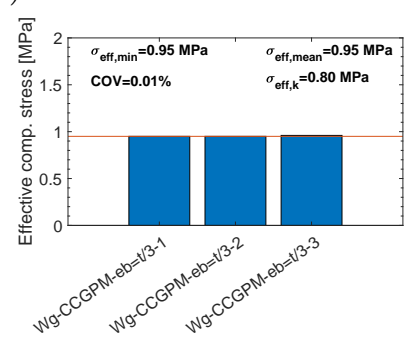

(e)

Figure 21: Effective compressive stress at failure for wallets with eccentricity 


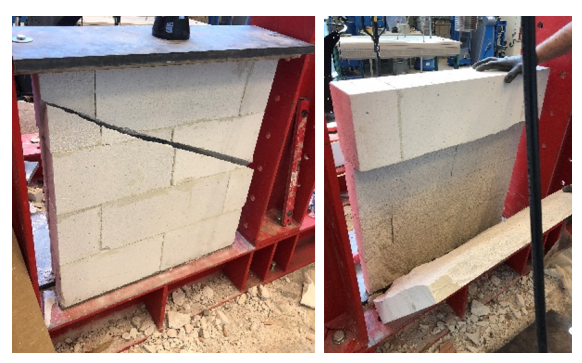

(a)
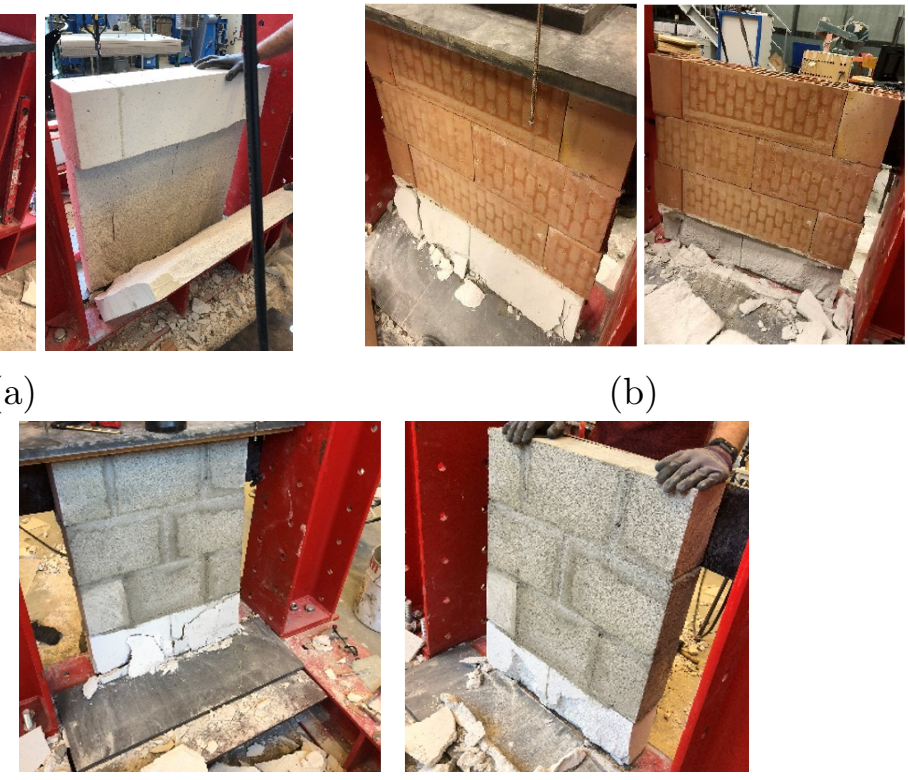

(b)

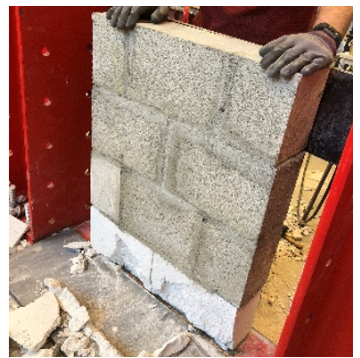

(c)

Figure 22: Failure pattern of wallets with eccentricity 


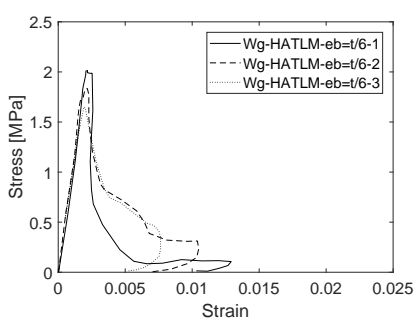

(a)

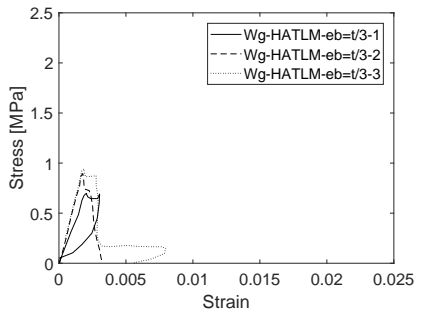

(b)

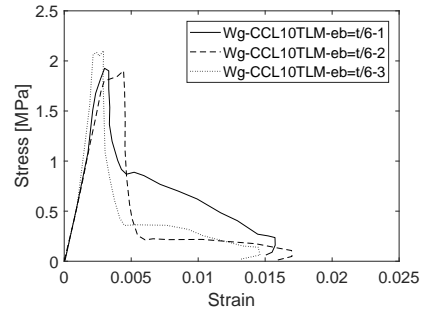

(c)

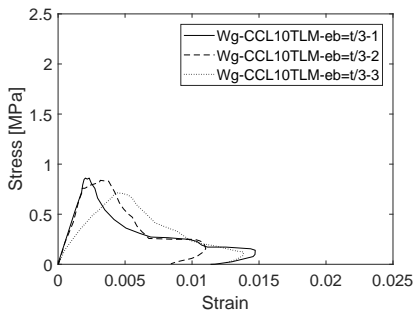

(d)

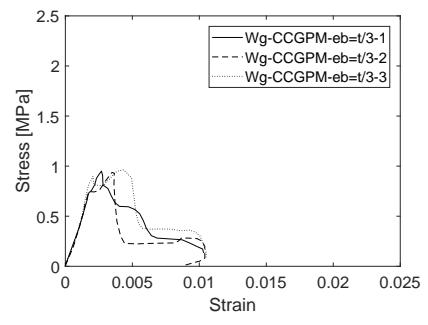

(e)

Figure 23: Stress strain curves for wallets with eccentricity: (a) homogeneous AAC with thin layer mortar with $\mathrm{e}=\mathrm{t} / 6$; (b) homogeneous $\mathrm{AAC}$ with thin layer mortar with $\mathrm{e}=\mathrm{t} / 3$; (c) composite AAC-clay 10 with thin layer mortar with $\mathrm{e}=\mathrm{t} / 6$; (d) composite AAC-clay 10 with thin layer mortar with $\mathrm{e}=\mathrm{t} / 3$; (e) composite $\mathrm{AAC}$-concrete with general purpose mortar with $\mathrm{e}=\mathrm{t} / 3$

\section{Discussion}

The test results in terms of mean and characteristic values of the compression strength of all tests on units, duplets and wallets (except cases with eccentricity) are summarized in Figure 24 in the form of a direct comparison between the homogeneous AAC specimens and the composite ones with a given mortar type. AAC units and homogeneous specimens are represented by the white bars, while composite specimens are represented by the gray bars. These results showed a good consistency between all sets of specimens, i.e. duplets and wallets constructed with or without quality control. The composite specimens exhibited a higher strength than the homogeneous ones. These conclusions are strengthened by the observations from tests with eccentricity stated in the previous section. This indicates that the bottom AAC course gains some strength when used in combination with other units of higher mechanical properties (i.e. stronger and stiffer). From this global comparison, it can also be noticed that AAC units alone led generally to 
the highest resistance value, followed by the duplets and finally by the wallets, with the exception on composite concrete wallets with good execution 465 (characterized by the highest strength among all combinations, see Figure 24c). These latter case could possibly be explained by the fact that the constraining effect coming from very rigid and perfectly assembled concrete blocks is at least as efficient as the constraint brought by the steel plates used as boundary elements for single unit tests. Table 5 presents the results

470 of the average vertical Young's modulus $E_{y}$ of the masonry walls with the corresponding mean or characteristic compressive strength. The results have generally highlighted that the walls with high values of young's modulus were characterized by larger values of compressive strengths and vice versa. For instance $E_{y}$ and $f_{m}$ ean for composite AAC-concrete walls with general pur475 pose mortar were equal to 870 and 2.66 MPa compared to 232 and $1.74 \mathrm{MPa}$ for homogeneous AAC wall with general purpose mortar. 


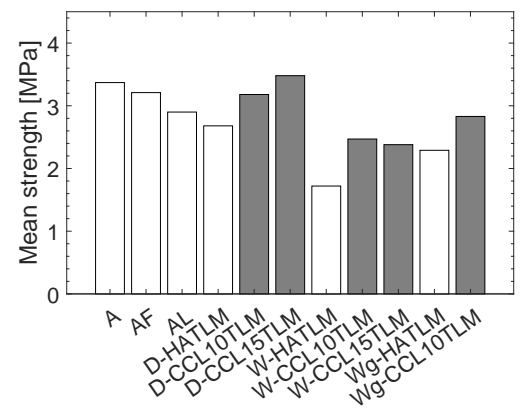

(a)

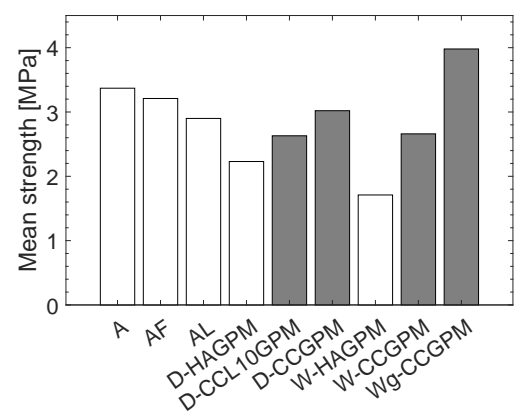

(c)

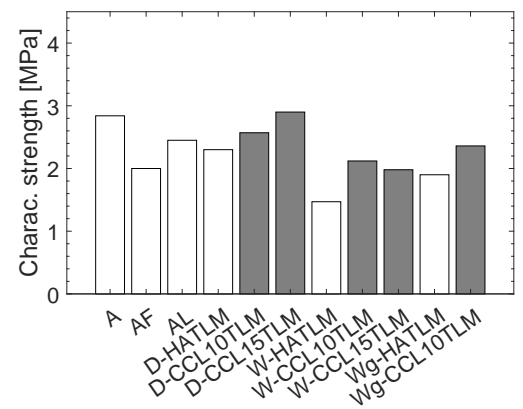

(b)

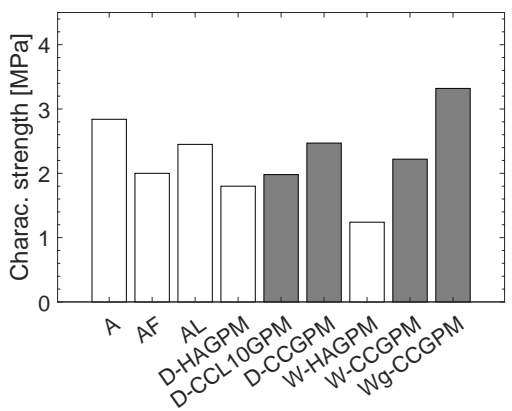

(d)

Figure 24: Compressive strength of masonry specimens: (a) mean strength for AAC units and specimens built with TLM ; (b) characteristic strength for AAC units and specimens built with TLM; (c) mean strength for AAC units and specimens built with GPM; (d) characteristic strength for AAC units and specimens built with GPM

Table 5: Young's modulus versus compressive strength of masonry walls

\begin{tabular}{cccc}
\hline Specimen & $\begin{array}{c}\text { Average } \\
\text { Young's modulus } \\
{[\mathrm{MPa}]}\end{array}$ & $\begin{array}{c}\text { Mean compressive } \\
\text { strength[MPa] }\end{array}$ & $\begin{array}{c}\text { Charactarestic compressive } \\
\text { strength[MPa] }\end{array}$ \\
\hline W-HAGPM & 232 & 1.71 & 1.24 \\
W-HATLM & 336 & 1.72 & 1.47 \\
W-CCL10TLM & 599 & 2.47 & 2.12 \\
W-CCL15TLM & 437 & 2.38 & 1.98 \\
W-CCGPM & 870 & 2.66 & 2.22 \\
\hline
\end{tabular}

To quantify the impact of the favorable interaction between $\mathrm{AAC}$ and 
main load-bearing elements, a simple interaction factor $\left(\mu_{m}\right.$ resp. $\left.\mu_{c}\right)$ has been defined as given in Equations 4 and 5. The ratio between composite and homogeneous configurations defined in these Equations has been evaluated based on the mean resp. characteristic compression strength for specimens having the same layout, loading condition and type of mortar.

$$
\begin{gathered}
\mu_{m}=\frac{\text { mean strength of the composite AAC masonry specimen }}{\text { mean strength of the homogeneous AAC specimen }} \\
\mu_{c}=\frac{\text { characteristic strength of the composite AAC masonry specimen }}{\text { characteristic strength of the homogeneous AAC specimen }}
\end{gathered}
$$

Table 6 presents the corresponding values derived from the test results. The values based on the mean strength are close to those based on the characteristic strength. However, the results in terms of characteristic strength are supposed to be more relevant to draw practical conclusions in terms of design. All the values are higher than 1.0, evidencing the favorable interaction, with an exception on composite AAC-clay with $\mathrm{e}=\mathrm{t} / 3$ (value derived based on the mean strength equal to 0.94). The values obtained for the wallets were also higher than those derived from the duplets. The values for both composite duplets and wallets built with concrete units were higher than the values for those built with clay units. The increase of the resistance appears thus to be associated with the constraining capacity of the main units: for AAC-concrete composite specimens, no visible cracks were observed in any of the concrete blocks during testing, corresponding to a strong constraining effect on the AAC layer. In comparison, for AAC-clay specimens, the propagation of several cracks was observed from the AAC layer to the abovelying clay blocks, leading to a globally less constraining effect. Moreover, the eccentricity influences the strength gained: the interaction factor decreases when the amplitude of eccentricity is increased. 
Table 6: Interaction factor $\mu_{m} / \mu_{c}$

\begin{tabular}{cccccc}
\hline Specimens & Duplets & $\begin{array}{c}\text { Poor } \\
\text { walls }\end{array}$ & $\begin{array}{c}\mu \\
\text { Good } \\
\text { walls }\end{array}$ & $\begin{array}{c}\text { Walls } \\
\mathrm{e}=\mathrm{t} / 6\end{array}$ & $\begin{array}{c}\text { Walls } \\
\mathrm{e}=\mathrm{t} / 3\end{array}$ \\
\hline $\begin{array}{c}\text { Composite concrete/ } \\
\text { Homogeneous AAC }\end{array}$ & $1.35 / 1.33$ & $1.56 / 1.79$ & $1.74 / 1.75$ & - & $1.12 / 1.14$ \\
\hline $\begin{array}{c}\text { Composite clay CL10 TLM/ } \\
\text { Homogeneous AAC TLM }\end{array}$ & $1.19 / 1.12$ & $1.43 / 1.44$ & $1.23 / 1.22$ & $1.08 / 1.08$ & $0.94 / 1.01$ \\
\hline $\begin{array}{c}\text { Composite clay CL10 GPM/ } \\
\text { Homogeneous AAC GPM }\end{array}$ & $1.18 / 1.11$ & - & - & - & - \\
\hline $\begin{array}{c}\text { Composite clay CL15 TLM/ } \\
\text { Homogeneous AAC TLM }\end{array}$ & $1.30 / 1.26$ & $1.38 / 1.35$ & - & - & - \\
\hline
\end{tabular}

The comparison between the homogeneous and the composite specimens in terms of reduction of the failure load due to the eccentricity of the base reaction is presented in Figure 25. For both homogeneous and composite wallets, the decreasing rate with increasing eccentricity follows the expected trend. It can also be seen that the strength of the composite wallets is always higher than the one of the corresponding homogeneous wallets. However, the strength reduction induced by the eccentricity with respect to the corresponding centered configuration is larger for the composite configurations than for the homogeneous ones. A comparison with a simple theoretical approach based on the ideal model of an homogeneous distribution of compressive stresses on the supported part of the wall, leading to a reduction factor equal to equal to $1-2 e_{i} / \mathrm{t}$ as for instance recommended by Eurocode 6 [37], shows that this approach yields safe values for homogeneous wallets with $\mathrm{e}=\mathrm{t} / 6$ or $\mathrm{t} / 3$ and composite specimens with $\mathrm{e}=\mathrm{t} / 6$. It appears however slightly unsafe for the composite specimens with $\mathrm{e}=\mathrm{t} / 3$ (strength of AAC concrete wall and AAC-clay were reduced by $76 \%$ and $72 \%$ respectively, which is equivalent to a strength reduction factor equal to 0.24 and 0.28 respectively, to be compared with the factor 0.33 obtained from the theoretical approach). The latter experimental observations provide a good trend of the global reduction due to eccentricity in a composite wall. However, to be able to adapt it in design codes, a broader experimental database would be desirable. 


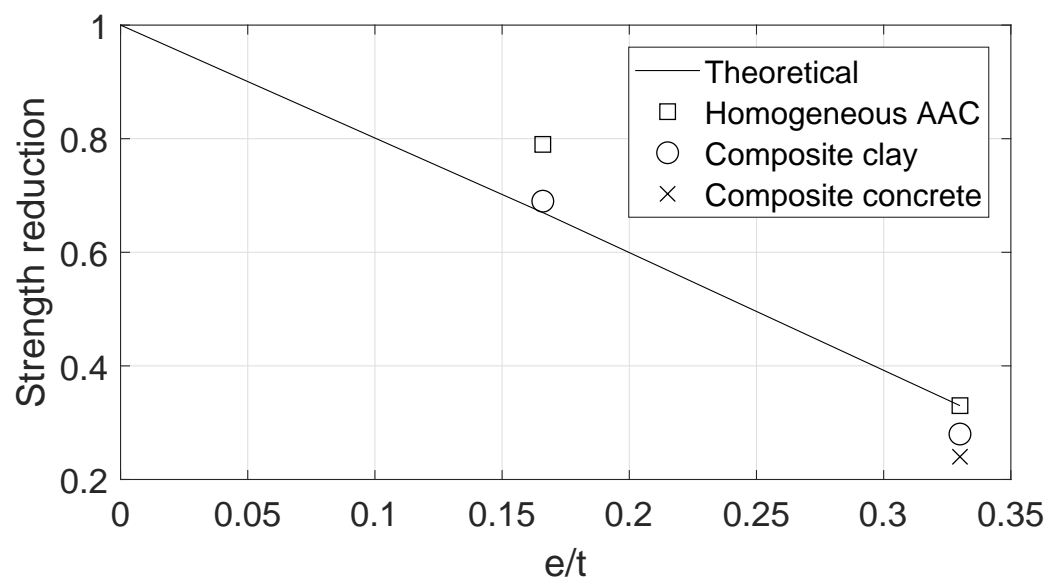

Figure 25: Failure load of masonry wallets with eccentricity referred to corresponding with centered reaction configuration

\section{Conclusion}

Experimental results on single units and on homogeneous and composite masonry duplets and wallets under uniaxial compression loads with or without eccentricity of the base reaction have been presented and discussed. The results show that duplets or wallets made of AAC units in combination with clay or concrete blocks, with a given mortar type, were characterized by a higher compression strength than the corresponding duplets or wallets made of AAC units only, indicating a favorable influence of the mechanical interaction between thermal and regular masonry units on the local resistance. The results show also that the resistance of composite specimens remain however in most cases lower than the resistance of single AAC units. Furthermore, the strength reduction due to the eccentricity with respect to a centered configuration has shown to be larger for the composite specimens than for the homogeneous ones, in particular for large amplitude of the eccentricity of the reaction (i.e. e $>t / 6$ ). Based on the observations obtained in the experiments summarized in this paper, practical conclusions can be drawn regarding the behavior and design of walls including an AAC layer at their basis. In all cases, the resistance of the composite wall was larger than its homogeneous AAC counterpart. Therefore, their design could be safely carried out assuming that the wall is entirely made of AAC units. The positive influence of the presence of the stiffer units (concrete or clay) on the 
545 use of a strength multiplier larger than unity applied to the characteristic strength of an equivalent homogeneous AAC wall. This multiplier has been shown as depending on the relative stiffness of both materials constituting the composite wall, on the internal structure of the clay or concrete block 550 and on the eccentricity of the compression load, ranging from 1,01 to 1,75, as given in Table 6. Results have also shown that a conservative estimate of the correction factor can be obtained from simple tests on duplets, namely applying an amplification factor $\mu$, derived from the characteristic values of the compressive strength obtained from tests on composite duplets referred 555 to duplets made of two stacked AAC units with the same mortar. Such small specimens are easier to fabricate, and the tests are easier to perform than an extensive wallet characterization. In the case of a resistance calculated from equivalent homogeneous AAC wallets or derived from tests on duplets, the eccentricity of the reaction can be taken into consideration with a clas560 sical reduction factor (as suggested in most masonry design codes) with an acceptable reliability level. 


\section{References}

[1] M. Tomazevic, Earthquake-resistant design of masonry buildings, Vol. 1, World Scientific, 1999.

565 [2] V. I. voor Bio-Ecologisch Bouwen en Wonen (VIBE), Bio-ecologisch bouwen, http: //www.vibe.be/bio-ecologisch-bouwen/gebouw, [Online; accessed 1-July-2016] (2016).

[3] WTCB, Thermische isolatie van bestaande muren, http://www .wtcb.be/homepage/ index.cfm?cat=information, [Online; accessed 1-July-2016] (2016).

[4] A. M. Papadopoulos, State of the art in thermal insulation materials and aims for future developments, Energy and Buildings 37 (1) (2005) 77-86.

[5] M. C. Limbachiya, J. J. Roberts, Autoclaved aerated concrete: innovation and development, Taylor \& Francis, 2005.

[6] W. GE, J. Yang, The study of the present situation of foam glass and development trend in china [j], Journal of Tangshan College 2 (2008) 026.

[7] V. is energie, Vergelijking van isolatiematerialen, http://www.energiesparen.be/ vergelijkingisolatiematerialen, [Online; accessed 1-July-2016] (2016).

[8] A. Laukaitis, B. Fiks, Acoustical properties of aerated autoclaved concrete, Applied Acoustics 67 (3) (2006) 284-296.

[9] D. Ferretti, E. Michelini, G. Rosati, Cracking in autoclaved aerated concrete: Experimental investigation and xfem modeling, Cement and Concrete Research 67 (2015) $156-167$.

[10] P. H. Feenstra, Computational aspects of biaxial stress in plain and reinforced concrete.

[11] B. Trunk, G. Schober, A. Helbling, F. Wittmann, Fracture mechanics parameters of autoclaved aerated concrete, Cement and Concrete Research 29 (6) (1999) 855-859.

[12] D. Martens, Thermal break with cellular glass units in load bearing masonry walls (2014).

[13] C. Mordant, M. S. Dietz, C. A. Taylor, A. Plumier, H. Degée, Seismic behavior of thin-bed layered unreinforced clay masonry shear walls including soundproofing elements, in: Seismic Evaluation and Rehabilitation of Structures, Springer, 2014, pp. $77-93$.

[14] Marmox, Marmox Thermo Block, http://www.marmox.co.uk, [Online; accessed 1July-2016] (2016). 
[15] L. Cavaleri, A. Failla, L. La Mendola, M. Papia, Experimental and analytical response of masonry elements under eccentric vertical loads, Engineering Structures 27 (8) (2005) 1175-1184.

[16] D. Tensing, Experimental study on axial compressive strength and elastic modulus of the clay and fly ash brick masonry, Journal of Civil Engineering and Construction Technology 4 (4) (2013) 134-141.

[17] J. Colville, Stability of unreinforced masonry under compressive load, TMS J 19 (1) (2001) 49-56.

[18] A. Brencich, C. Corradi, L. Gambarotta, Eccentrically loaded brickwork: Theoretical and experimental results, Engineering Structures 30 (12) (2008) 3629-3643.

[19] E. Fortes, G. Parsekian, J. Cammacho, F. Fonseca, Compressive strength of masonry constructed with high strength concrete blocks, Revista IBRACON de Estruturas e Materiais 10 (6) (2017) 1273-1319.

[20] D. Theodossopoulos, B. Sinha, A review of analytical methods in the current design processes and assessment of performance of masonry structures, Construction and Building Materials 41 (2013) 990-1001.

[21] H. B. Kaushik, D. C. Rai, S. K. Jain, Stress-strain characteristics of clay brick masonry under uniaxial compression, Journal of materials in Civil Engineering 19 (9) (2007) 728-739.

[22] J. M. Adam, A. Brencich, T. G. Hughes, T. Jefferson, Micromodelling of eccentrically loaded brickwork: Study of masonry wallettes, Engineering Structures 32 (5) (2010) $1244-1251$.

[23] C. Sandoval, P. Roca, E. Bernat, L. Gil, Testing and numerical modelling of buckling failure of masonry walls, Construction and Building Materials 25 (12) (2011) 43944402.

[24] A. Brencich, G. de Felice, Brickwork under eccentric compression: Experimental results and macroscopic models, Construction and Building Materials 23 (5) (2009) $1935-1946$.

[25] G. L. Al-Chaar, A. Mehrabi, Constitutive models for nonlinear finite element analysis of masonry prisms and infill walls, Tech. rep., DTIC Document (2008).

[26] C. Mordant, V. Denoël, H. Degée, Comparison of experimental results and numerical modelling of unreinforced load-bearing masonry structures subjected to earthquake loading, SECED 2015 Conference: Society for Earthquake and Civil Engineering Dynamics, 9-10 July 2015. 
[27] P. B. Lourenço, K. Palácio, F. Prieto, Implementation of a constitutive model for masonry shells as a stand-alone subroutine, Tech. rep., Technical Report Report 02DEC/E-13, University of Minho (2002).

[28] P. B. Lourenço, Anisotropic softening model for masonry plates and shells, Journal of Structural Engineering 126 (9) (2000) 1008-1016.

[29] L. Macorini, B. Izzuddin, A non-linear interface element for 3d mesoscale analysis of brick-masonry structures, International Journal for numerical methods in Engineering 85 (12) (2011) 1584-1608.

[30] N. Augenti, F. Parisi, Constitutive models for tuff masonry under uniaxial compression, Journal of Materials in Civil Engineering 22 (11) (2010) 1102-1111.

[31] G. Magenes, A. Fontana, Simplified non-linear seismic analysis of masonry buildings, in: Proc. Br. Masonry Soc. No. 8, 1998, pp. 190-195.

[32] F. Parisi, N. Augenti, Assessment of unreinforced masonry cross sections under eccentric compression accounting for strain softening, Construction and Building materials 41 (2013) 654-664.

[33] T. J. Sullivan, G. M. Calvi, Developments in the field of displacement-based seismic assessment, EUCENTRE, 2013.

[34] F. Parisi, Seismic design of box-type unreinforced masonry buildings through direct displacement-based approach, The Open Construction and Building Technology Journal $10(1)$.

[35] J. E. Tanner, J. L. Varela, R. E. Klingner, M. J. Brightman, U. Cancino, Seismic testing of autoclaved aerated concrete shearwalls: a comprehensive review, ACI structural journal 102 (3) (2005) 374.

[36] M. Gams, Seismic behaviour of confined autoclaved aerated concrete masonry buildings: a shaking table study, Mauerwerk 14 (3) (2010) 153-160.

[37] European Committee for standardization Eurocode 6. Eurocode 6: Design of masonry structures. Brussels, Belgium, 2005.

[38] EN 772-1. Methods of test for masonry units. Part 1: Determination of compressive strength. European Committee for Standardization. Brussels, Belgium, 2011.

[39] EN 1052-1. Methods of test for masonry. Part 1: Determination of compressive strength. European Committee for Standardization. Brussels, Belgium, 1998.

660 [40] NBN EN 1996-1-1+A1 ANB. Eurocode 6 - Design of masonry structures - Part 1-1 : General rules for reinforced and unreinforced masonry structures - National annex. Brussels, Belgium, 2016. 